\title{
A New Anatomy of the Retirement Process in Japan
}

\author{
By
}

Satoshi Shimizutani*

This version: October 2009

This study was undertaken in a research project exploring the interaction between the pension program, retirement, and the well-being of the elderly, supported by Health and Labour Sciences Research Grants (FY2007-FY2008) and the Project on International Equity (FY2006-FY2010) supported by the Ministry of Education, Culture, Sports, Science and Technology. We are grateful to the Ministry of Health, Labour and Welfare for providing us a micro-level dataset from the Survey on Employment of the Elderly. We also thank Hideki Hashimoto, Hidehiko Ichimura, and Takashi Oshio for their useful comments. The views expressed in this paper are personal.

* Corresponding author; Senior Research Fellow, Institute for International Policy Studies; Toranomon 30 Mori Building $6^{\text {th }}$ floor, Toranomon 3-2-2, Minato-ku, Tokyo Japan 105-0001; Tel: +81-3-5404-6651, FAX: +81-3-5405-6650; E-mail: sshimizutani@iips.org 


\begin{abstract}
$\underline{\text { Abstract }}$
In Japan, retirement is a gradual process that transpires over a particularly long period of time. Using large scale micro-level datasets from the Survey of Employment of the Elderly compiled by the Japanese government, we provide some stylized facts on the development of retirement behavior since the 1980s and explore factors affecting the individual retirement decision. First, we observed a general declining trend in the proportion of retired individuals aged 55-59 (especially females) while the proportion of retired individuals aged 65-69 (especially males) increased. Second, the survival analysis on actual retirement age shows that males who worked as an expert/technician or manager before retirement or individuals receiving a larger public pension income are likely to retire earlier. Third, another survival analysis on expected retirement age shows that workers with lower job satisfaction in terms of rewards and males with a larger family size are more likely to retire earlier.
\end{abstract}

Keywords: retirement, labor supply of the elderly, survival analysis, Japan.

JEL Classification Codes: J14, J26. 


\section{Introduction}

Retirement is a gradual process. In Japan, it begins with leave from a career job and eventually concludes with the decision to leave the labor force permanently. The process is lengthy and is affected by a variety of factors including economic, health, family, and other circumstances.

The usual starting point in the retirement process is separation from a career job, which in Japan often takes the form of mandatory retirement, increasingly prevalent in recent years encouraged by policies to employ the elderly. In 1980, the proportion of firms employing 30 or more workers that had in place a mandatory retirement practice was 60 percent; after 2000, the percentage increased to nearly 100 percent. The most dominant mandatory retirement age currently is 60. If the scope is widened to include smaller firms, the proportion of employees subject to mandatory retirement was approximately 60 percent for males and 40 percent for females in 2000 (Shimizutani and Oshio (2009)). On the other hand, permanent leave from the labor force is the last phase of the retirement process. In Japan, the average effective retirement age for males is 69.5 years and for females 66.5 years, both of which are the latest ages among OECD countries (OECD (2008)). It is worth noting that the average retirement age of males is both remarkable in and of itself as well as being higher than that for Sweden, the second highest, by 3.8 years.

Seen together, the prevalence of mandatory retirement at around age 60 and subsequent 
leave from the labor market in the late 60s implies that the retirement process is particularly lengthy in Japan, especially for male workers. The unusually long duration of the retirement process is considered one of the most distinct features of the Japanese elderly labor market and acknowledged to require in-depth analysis. ${ }^{1}$ This study aims to provide new systematic empirical evidence on when and how Japanese workers retire in order to enhance understanding of the retirement process of the world's latest retirees. This study emphasizes fact-finding of retirement behavior and performs three sets of analysis to provide a new anatomy of the retirement process in Japan. First, using macro- and micro-level data, we present several retirement measurements that show new developments in retirement since the 1980s. Second, we employ a survival analysis to explore factors affecting the actual retirement age by examining the difference in hazard rates across a variety of groups. Third, we examine determinants of the expected age that current workers will retire. The advantage of this analysis is that it explores the effect of current health, job, and family status on the retirement decision, and thus complements the analysis of the actual retirement age.

The paper proceeds as follows. The next section describes the dataset used in this study. Section 3 presents some basic facts about developments in retirement behavior since the 1980s. Section 4 explores factors affecting the actual retirement age by examining the difference in the hazard rate across groups, and Section 5 employs a similar analysis for the

\footnotetext{
${ }^{1}$ For example, the role of firms in initial post retirement arrangements was examined by Clark and Ogawa (1997), Rebick (1995), and Shimizutani and Oshio (2009). See Lazear (1986) and Lumsdaine and Mitchell (1999) for a comprehensive survey on retirement.
} 
expected retirement age. The last section summarizes our findings.

\section{Data description}

This study uses micro-level data from the Survey on Employment of the Elderly (henceforth, the SEE survey), compiled by the Ministry of Health, Labour and Welfare (formerly Ministry of Labour), Government of Japan. The individuals in the sample were aged between 55 and 69 randomly chosen from all regions in Japan. The SEE survey has been performed every four or five years and the sample size is 20,000-30,000 depending on the survey year. ${ }^{2}$ In this study, we describe the development of retirement behavior using micro-level data from the surveys conducted in 1983, 1988, 1992, 1996, 2000, and 2004 and perform survival analysis on actual and expected retirement age using the 2000 survey since that year's survey contains information on specific retirement age that is indispensable to the hazard analysis.

To our knowledge, the SEE survey is one of the few datasets in Japan that contains essential information on developments in retirement behavior. One feature of the survey is that it provides multiple variables including the individual's characteristics, current employment status, actual and expected retirement age, and social security eligibility and benefits. Another feature of the survey is that the sample size is large enough to enable construction of cells by age and gender, which permits us to perform in-depth analysis on

2 The total sample size was reduced to 19,595 in the 2000 survey and 17,853 in the 2004 survey. 
retirement trends. The sampling design has remained unchanged year to year and the questions related to retirement are for the most part consistent, which is suitable for depicting "basic facts” on a long-run development of retirement covering two decades, during which time large economic fluctuations and a variety of social security reforms were witnessed.

\section{Developments in retirement behavior in Japan}

In this section, we use macro- and micro-data to provide the proportion of the retired and show new developments in retirement behavior though several measurements. First, we provide macro-evidence on the trends of the labor force participation (LFP) rate, which is often used to summarize retirement behavior. Figure 1 reports the labor force participation rate by age group (55-59, 60-64 and 65-69) and sex. The source of this data is the publicly available tabulation of the Labor Force Survey (Roudou ryoku chosa) compiled by the Government of Japan. The upper panel shows that the LFP rate of males aged 55-59 exceeds 90 percent and levels off and that of males aged 60-64 varies between 70-80 percent with a sharp rise in 2007. In contrast, the LFP rate of males aged 65-69 has been on a declining trend with some recovery since 2005. The lower panel shows that the LFP rate of females aged 55-59 has been increasing since the mid-1980s and those of females aged 60-64 and 65-69 level off with a modest recovery in recent years. Among these trends, it is worth noting the decline of the LFP rate of males aged 65-69 and the rise of the LFP rate of females 
aged 55-59.

Next, we turn to the developments in retirement by age and sex using the SEE survey in six different years between 1983 and 2004. Since the concept of retirement is rather complex, it needs to be defined before proceeding. In fact, there are a number of ways to define "retirement" depending on the purpose of the topic to be examined (Lazear (1986)). Thus, we will use five different retirement measurements available in the survey, though some definitions are not consistently available through all six surveys. ${ }^{3}$

Definition 1 is the state in which a respondent has already permanently stopped working for a salary. The 2000 and 2004 SEE surveys pose the question as follows: "Have you ever considered permanently discontinuing a salaried job or have you already permanently stopped working for a salary?” While the implicit definition of "work for salary” or "permanently" depends on the identity and point of reference of the respondent, the answer to the question is a starting point to explore retirement behavior. Figure 2(1) shows that the proportion of retirees by this definition increases with age and is consistently smaller for males than females in all ages. In 2000, the proportion for males increased from 9 percent (21 percent for females) at age 60 to 37 percent (44 percent) at age 69. At a closer look, the

\footnotetext{
${ }^{3}$ See Gustman, Mitchell, and Steinmeier (1995) for several retirement measures using HRS, though a direct comparison with this analysis is not possible due to different age ranges (51-60 in their paper). A popular definition is an affirmative answer to a question regarding retirement status like "Are you currently retired?”(Lazear (1986)). The other definitions in Lazear (1986) are (1) the individual is out of the labor force with the intention of remaining out permanently, (2) the individual has reduced his hours substantially from some lifetime average and intends to maintain hours at or below the current level, (3) the individual receives some of his income as pension benefits, (4) the individual appears on some company's retirement role, and (5) the individual receives a primary social security payment.
} 
proportion of males levels off in the 50s, jumps at age 60, and is followed by an upward slope in the 60s. The proportion of females jumps at around age 60-61 after which a similar but slightly flatter slope is seen. It is clear that the proportion is much larger in 2004 than in 2000 for both sexes but the difference may derive from the lack of standardization among the choices, even though the wording of the question and that of two of the three possible answers is the same. ${ }^{4}$ Thus, although the wording is more objective than the typical "are you currently retired?” phrasing, it is still important to be careful when interpreting the proportion of retirees answering this type of question.

Definition 2 refers to the state in which a respondent usually does not work. The 1992, 2000, and 2004 SEE surveys ask: "How do you usually spend your time?” with three choices "I usually work," "I work sometimes but it is not my main activity,” and "I do not usually work." Figure 2(2) illustrates that the proportion of males in their 50s who do not usually work is less than 10 percent, then jumps at age 60, and then tracks an upward slope. While the proportion is similar across years, the proportion after age 60, especially in the second half of the 60s, is larger in 2004. On the other hand, the proportion of female retirees by this definition increases in the 50s but is smaller in recent years than it was in 1992. At age 60,

\footnotetext{
${ }^{4}$ While two of the three choices are the same ("I have thought about the age when I would permanently leave my salaried job" and "I have already quit a salaried job"), the remaining possible answer in 2000 was "I have never thought about permanently leaving my salaried job," and in 2004 "I will continue to work regardless of my age.” The share of the latter exceeds the former especially for females.

5 The 1983, 1988, and 1996 surveys pose the same question and the same answer choices but they addressed the question solely to respondents who had actually worked for a salary in the month just prior to the survey and thus the proportion is small.
} 
the proportion is around 50 percent after a larger jump and in recent years is slightly larger in the 60s. In other words, males are more likely to retire in the late 60s and females are less likely to retire in their 50s.

Definition 3 is the state in which a respondent neither worked nor searched for a job in the previous month, a category which corresponds to "out of the labor force.” While those who are currently out of the labor force are not always retired since some individuals are just temporarily out of work, the series of the variable is consistently available for all six surveys and thus is useful to depict the long-term trends of retirement. Another advantage of this definition is that we can track the same cohort for two decades and observe developments in retirement. We chose three representative cohorts whose observations were available at four points in time: those who were born in 1928 (age 55 in the 1983 survey), in 1932 (age 55 in the 1988 survey), and in 1937 (age 55 in the 1992 survey). Figure 2(3) shows that the proportion of males declines in the youngest cohort (1937 cohort) at ages 55 and 60 but increases at ages 64 and 68, and that the proportion of females is smaller for the 1933 and 1937 cohorts at ages 55 and 60 and is smallest for the 1937 cohort at age 68 . The development in retirement expressed by Definition 3 is similar to those for males in Definitions 1 or 2, excepting the lower proportion of females in the 50s.

Definition 4 is the state in which a respondent is working at reduced hours. The SEE survey asked the workers regarding the status of their working hours (whether or not they 
were regular) and asked the unemployed about their desire to seek a part-time or temporary

job. Thus we define "non full-time workers" as encompassing three categories: workers with shorter working hours, job seekers searching for a temporary job, and those out of the labor force (Definition 3). Obviously, this definition is broader than Definition 3 and enables us to capture the status of "working retirement."6 Figure 1(4) reports that the proportion of the youngest male cohort (1937 cohort) is always higher than that of the older generations except at age 55. In contrast, the shape is the reverse for females: the proportion is higher for the youngest cohort at ages 55 and 60 but lower at ages 65 and 68. The higher proportion of females, especially in the 50s, may reflect a general trend of increased female labor supply, not an increase in the proportion of the retired.

Lastly, Definition 5 is the state in which a respondent currently receives some kind of public pension benefits. This is an objective definition of retirement and is affected by institutional features like a change in the pension eligibility age. ${ }^{7}$ Some individuals who are aged 60-64 and eligible to receive Employee’s Pension Insurance benefits do not receive the

\footnotetext{
6 At the same time, working for shorter hours is not always interpreted as a form of retirement, especially for workers in their 50s.

7 The Japanese public pension comprises flat rate and wage-proportional components. For male pensioners, the eligibility age for both flat rate and wage-proportional benefits was 60 between 1973 and 2000. The eligibility age for the flat-rate component has been scheduled to increase since 2001 by one year for every three years to 65 in 2013, while that for the wage-proportional is scheduled to rise by one year every three years from 2013 to 65 in 2025. For female beneficiaries, the eligibility age was 55 until 1985, and then was raised to 60 in 1999. The eligibility ages are set to increase, albeit with a five-year lag for men: from 2006 for the flat-rate benefit and from 2018 for the wage-proportional benefit. Since the 1985 reform, an increase in total pension benefits has been held down (Oshio, Shimizutani and Oishi (2008) for the detailed description).
} 
benefit if they earn more than a threshold due to the social security earnings test. ${ }^{8}$ Figure 2(5) shows that the proportion is smaller in more recent years, for both males and females. This is a direct effect of the extension of the eligible age for public pension benefits. Moreover, a large jump around 60 is observed. The proportion jumps to about 50 percent of males and 40-50 percent of females. Between ages 61 and 64, the proportion is on a moderate increase trend and the gradient is steeper for females. At age 65, another hike is observed and, after 65, the proportion exceeds 90 percent. The proportion of females after age 65 is slightly higher in more recent years.

So far, we have examined the developments in the retired proportion using the macro-level LFP rate and the five different definitions of "retirement.” While we see some small variations in the trends according to definition, these simple observations reveal a general pattern in the development of retirement over the period of two decades: the proportion of the female retired declined in the 50s but that of the male retired increased in the second half of the 60s. Considering the extension of longevity and eligible age to receive public pension benefits, it is natural to see the decline in the proportion of the retired in the 50s, a development which may be also supported by the general increase in the female labor supply. In contrast, it is somewhat puzzling that the proportion of the male retired increased in the second half of the 60s. This finding poses a challenge for policymakers since those

\footnotetext{
${ }^{8}$ For those who are aged 60-64, the amount of public pension benefits is reduced to zero if the amount of labor income (or the sum of labor income and wage-proportional benefit since 2002) exceeds a limit. In contrast, the pension income is not reduced to zero for those who are aged 65-69 since the highest "effective tax" on pension income is not 100 percent for those workers.
} 
who are aged 65-69 are the next policy target for stimulation of the labor supply of the elderly.

\section{Distribution and determinants of actual retirement age}

This section explores the distribution of the actual retirement age. We use the term

"actual retirement age” for those who have already retired to differentiate from "expected retirement age” referring to those who have not retired yet. In the United States, using the Retirement History Survey (RHS) in the 1970s, Rust (1989) found “twin peaks” in the retirement ages for older Americans who file for social security benefits. The two peaks are observed at age 62 when the individual is eligible to receive a reduced benefit and at age 65 when the individual is eligible to full social benefits. The two marked peaks remain after controlling for pension income available at those ages (Lumsdaine and Mitchell (1999)).

The 2000 and 2004 SEE surveys inquired the actual retirement age of those who had already stopped working for salary. ${ }^{9}$ The wording of the question is the same in both surveys but the response method varies: in the 2000 survey, the respondent fills in a specific retirement age, and in the 2004 survey the respondent chooses one age from among eight choices. In the following analyses, we confine the sample to those who had a job at age 55. Those who were not retired at the time of the surveys are excluded when describing the

\footnotetext{
${ }^{9}$ In the years prior to 2000, the SEE survey asked workers when they intend to retire and job seekers when they plan to leave a job if are able to obtain a desirable job, but the survey does not ask the retirement age for those who are currently out of labor force.
} 
distribution of the actual retirement age but are included in the survival analysis as censored samples. $^{10}$

The upper panel in Figure 3 presents the distribution of the actual retirement age in 2000. We have several observations. First, a single and large hike is observed at age 60, for both males and females, while the concentration is larger for males (43 percent) than females (26 percent). Second, the proportion of individuals who retired in their 50s is much higher for females (47 percent) than males (17 percent). Third, the proportion of those who retired in their 60s is always higher for males than females with a small jump close to 10 percent at age 65. The lower panel of Figure 3 reports the distribution of actual retirement ages in 2004. While the reporting method varies in the two surveys, we observe a similar pattern in 2004 to that in 2000. The most frequent retirement age is age 60, for both males (39 percent) and females ( 27 percent). The share of those who retired in their 50 s is larger for females (45 percent), or more than double of that for males (18 percent), who show a very small hike at age 65.

We turn to survival analyses to explore factors affecting retirement age using the 2000 survey in which a specific retirement age is provided. We employ a nonparametric method (Kaplan-Meier survival estimates) by groups and compare the difference in equality of the

\footnotetext{
${ }^{10}$ The eight categories in the 2004 survey are (1) 54 or less, (2) 55-59, (3) 60, (4) 61, (5) 62, (6) 63, (7) 64, (8) 65 and (9) 66-69. Since we confine the sample to those who had a job at age 55, the choice of (1) is discarded in the analysis. We cannot identify whether the small changes between the two surveys are caused by change in retirement behavior in the four years or by the different way to respond.
} 
survival functions by the log-rank and Wilcoxson (Breslow) tests. ${ }^{11}$ The sample in the survival analysis includes those who have not retired at the time of the survey as a truncated sample. The $\mathrm{X}$ axis in Figure 4s stands for the years from age 55 (the maximum is 14 corresponding to age 69 which is the end of the observation time) and the $\mathrm{Y}$ axis stands for estimated survival rates. $^{12}$

Figure 4(1) reports the survival estimates by educational attainment. The upper panel shows that the survival rate of males stays close to 100 percent in the 50 s for males with some educational attainment but is consistently smaller for males with higher educational attainment. The survival rate at age 69 is 53 percent for junior high school graduates, 45 percent for senior high school or two year college graduates, and 30 percent for university or more graduates. The lower panel reveals the same pattern for females: the survival rate is smaller for higher educated females. The equality of the survival functions is rejected at 1 percent significance for both males and females and is rejected even if the first two categories (non university graduates) are merged except for the log-rank test for females.

Figure 4(2) shows the survival estimates by job type before retirement. We classify the job types into (1) experts and technicians, (2) management, and (3) on-site workers including production workers. The survival estimates of males are lower for those who were managers,

${ }^{11}$ Seike and Yamada (2004) perform a similar analysis for males using a different data set collected in 1993. Rebick (1995) pointed out that the sample in the data set is not nationally representative and oversamples the individuals who worked for large or manufacturing firms.

${ }^{12}$ As is clear from Figure 3, the Kaplan-Meier survival rate is higher for males than females and the equality of the two estimates are rejected at 1 percent significance. To save space, we omit the presentation of the estimates by sex. 
implying that former managers are more likely to retire earlier. The estimates show that indeed the equality of the survival functions across job types is rejected. In contrast, the equality of survival functions is not rejected for females. These observations are unchanged if the first two categories (experts/technicians and managers) are merged and on-site workers and desk workers are compared. However, if we compare non production workers and production workers, the equality of survival estimates are not rejected even for males, implying that there is a large gap in the retirement age between on-site and non on-site workers (the results are omitted).

Figure 4(3) shows the survival estimates by the amount of public pension benefits. The SEE survey asked whether a respondent received public pension benefits and, if so, how much by type of insurance (Employees’ Pension Insurance (Kosei Nenkin), National Pension Insurance (Kokumin Nenkin) and Mutual Aid Insurance (Kyosai Nenkin)). We sum up the public pension benefits and classify the sample into those who received 150,000 yen (median) or more and those who received less than 150,000 yen. We observe a clear pattern that those who received a larger amount of public pension benefits are more likely retire earlier, for both males and females. The equality of survival functions is rejected at 1 percent significance. The survival estimate at age 69 is 35 percent for males with a larger amount of public pension income and 61 percent for males with a smaller amount, and the gap is smaller for females (46 percent and 27 percent at age 69). This pattern is consistent with previous 
works which found a discouraging effect of public pension income on labor supply of the elderly (Oshio, Oishi, and Shimizutani (2009)). In addition, the SEE survey asked the same question about the company-provided pension program (the third tier) and private pension program. While there is no significant difference in the survival estimates between individuals entitled to receive private pension benefits and those who are not, the survival estimates are significantly smaller for individuals in a company-provided pension program (the results are omitted to save space).

In sum, the survival analysis on the actual retirement age shows that males who were an expert/technician or manager before retirement or individuals that receive a larger public pension income are likely to permanently leave the labor force earlier. In contrast, educational attainment is not associated with timing of retirement. ${ }^{13}$

\section{Distribution and determinants of expected retirement age}

This section explores factors affecting the expected age to retire for those who have not yet retired. One advantage to examining the expected retirement age is the ability to connect the retirement age to the information on the current status. It is difficult to obtain the

\footnotetext{
${ }^{13}$ While it is common that individuals entitled to receive a larger amount of public pension benefits are more likely to retire earlier, our results are different from Seike and Yamada (2004) which report that non university graduates or people engaged on on-site work or private pensioners are more likely to retire earlier. A possible explanation for the gap is the difference in the timing of the survey, the coverage of the analysis time and the sampling design. Seike and Yamada (2004) used a dataset which was collected in 1993, was not nationally representative, and covered the analysis time between 55 and 73 years of age. In contrast, this study uses a dataset which was collected in 2000 and is nationally representative and covered the analysis time between 55 and 69 .
} 
information critical to the retirement decision from those who have retired previously. One possible way using cross section data is to choose individuals who retired recently, but doing so makes the sample size smaller; furthermore, an individual's perception may vary before and after retirement. Instead, we will examine the expected retirement age collected in the 2000 SEE survey for those who have not yet retired. In particular, we focus on three elements of the retirement decision: health status, job satisfaction, and family demographics. In this analysis, we confine the sample to those who provided their expected retirement age. ${ }^{14}$ The $\mathrm{X}$ axis of Figure 5 s stands for years from age 55 and the $\mathrm{Y}$ axis stands for survival estimates.

Figure 5(1) shows the Kaplan-Meier survival estimates by self-reported health status. The 2000 SEE survey asked respondents to choose one of the three categories of subjective current health status: healthy, not healthy, and sick. We merge the individuals choosing the last two choices and divide the sample into categories of the healthy and the unhealthy. In general, health status is one of the important factors affecting the retirement decision (Lumdaine and Mitchell (1999)). Contrary to the prevailing view, the equality of the survival functions is not rejected for males. At a closer look, the survival rate of the healthy is indeed smaller for the unhealthy up to age 65 but this is not the case for 65 and over. Moreover, the survival rate of females is higher for the unhealthy, which is paradoxical. Those observations

\footnotetext{
${ }^{14}$ Another idea is to include the respondents who chose "I have never thought about permanently leaving my salaried job" as the censored sample in the survival analysis. However, the meaning of the choice is ambiguous and the respondent may or may not think that he/she will not leave a job as long as he/she lives.
} 
are unchanged if we use the original three categories. ${ }^{15}$

Figure 5(2) and (3) show the survival estimates by job satisfaction for males and

females, respectively. The 2000 SEE survey asked incumbent workers about their job

satisfaction in terms of six aspects: 1) earnings, 2) working hours, 3) workplace

equipment/environment, 4) human relationships at the workplace, 5) utilization of skills and

knowledge, and 6) job achievement. The respondents were required to choose one of the five

responses: very satisfied, satisfied, neutral, dissatisfied, or very dissatisfied. We form two

groups of the satisfied (very satisfied or satisfied) and the dissatisfied (dissatisfied or very

dissatisfied) and exclude those who reported neutral from either category. ${ }^{16}$ We have several

observations. First, workers who are satisfied with earnings are more likely to retire earlier

and the equality of survival functions is rejected at 10 percent significance. This result seems

to be counter-intuitive but may be explained by the income effect: higher earnings may

reduce the labor supply. Second, there is no significant difference in the survival estimates

with respect to satisfaction with working hours. Third, workers who are satisfied with

\footnotetext{
${ }^{15}$ Seike and Yamada (2004) examined the survival estimates of actual retirement age by current health status. We apply the survival analysis by the current health status to actual retirement age and indeed find that a healthier individual is more likely to retire late, whether male or female, and the equality of the survival functions is rejected at 1 percent significance. However, it is not plausible to assume that the current health status is associated with the retirement decision made several years ago unless the perception of health status is unchanged. Rather, the result implies that a person enjoying a good heath status now is more likely to retire late.

${ }^{16}$ Job stress measures are well-developed as represented by the demand-control model (the Karasek measure) and the effort-reward imbalance model (the Siegrist measure). Unfortunately, the SEE survey is not designed to enable us to make those job quality measures. However, conceptually, earnings, human relationships at the workplace, utilization of skills and knowledge, and job achievement stand for "reward" in the effort-reward imbalance model and workplace equipment/environment stands for "demand" in the demand-control model. There is no measure corresponding to control (discretion) or effort in the SEE survey. We would like to express appreciation to Hideki Hashimoto for this suggestion.
} 
workplace equipment/environment, human relationships at the workplace, utilization of skills and knowledge, and job achievement are significantly more likely to retire late. This result shows that job quality is one important factor in the retirement decision and sufficient non monetary rewards to workers defer the timing of retirement. In particular, the equality of the survival estimates of males in terms of human relationships at the workplace, utilization of skills and knowledge, and job achievement are overwhelmingly rejected at 1 percent significance (10 percent significance for workplace equipment/environment). The equality of the survival estimates of females in terms of human relationships at the workplace and job achievement is rejected at 1 percent significance but that in workplace equipment/environment and utilization of skills and knowledge are not rejected by the log-rank test.

Lastly, Figure 5(4) shows the survival estimates by family size. The SEE survey does not ask any question about the respondents' marital status but it does inquire about the number of persons living together. We divide the sample to those whose family size is one or two including the respondent and to those whose size is three or more. The survival estimates of males are larger if family size is smaller and the equality of the survival functions of males is rejected at 1 percent significance (not rejected for females by the log-rank test). Since a respondent whose family size is one or two is likely to be single or a married couple living without parents or children, the observation may reflect that a respondent independent of 
parents or children is more likely to retire later and a respondent with a larger number of persons living together is more likely to retire earlier probably due to the preference to spend time with family members. In contrast, if we divide the sample to those with one wage earner and to those with two or more earners, the difference in the survival functions is not statistically significant (the results are omitted).

In sum, the survival analysis on the expected retirement age shows that individuals who are satisfied with their job in terms of non monetary rewards, whether male or female, or males with a larger number of persons residing together are more likely to retire later. In contrast, the current self-reported health status is not significantly associated with expected retirement age.

\section{Conclusion}

We should recognize that retirement can be a long, gradual process and the intermediate status which is neither full-time work nor complete leave from the labor force is dominant for the elderly. This is especially the case for Japan since the average duration of the transition process is unusually long. Moreover, the employment status for the elderly depends on a variety of individual attributes and there are a variety of pathways from primary job to retirement.

We utilize a large scale micro-level dataset from the Survey of Employment of the 
Elderly compiled by the Japanese government to provide "stylized facts" on the development of retirement behavior in Japan since the 1980s and explore factors affecting the individual retirement decision. Our empirical results show general declining trend in the proportion of retired individuals aged 55-59 (especially females) while the proportion of retired individuals aged 65-69 (especially males) increased. Moreover, the survival analysis on the actual retirement age shows that males who worked as an expert/technician or manager before retirement or individuals receiving a larger public pension income are likely to permanently leave the labor force earlier but that educational attainment is not significantly associated with the timing of retirement. Moreover, another survival analysis on expected retirement age shows that job satisfaction in terms of non monetary reward and smaller family size motivate individuals to work longer but the current self-reported health status is not significantly associated with retirement age.

This study emphasized fact-finding of retirement behavior over a period of two decades. While the SEE survey has the advantage of covering developments in retirement since the 1980s and is indeed the best available data to explore the labor supply of the elderly, we acknowledge the limitations of the analysis using cross-sectional data. The stylized facts should be investigated again if a longitudinal dataset is constructed in Japan and tracks the same person for more years. Fortunately, a new endeavor on constructing large scale panel data on retirement and health in Japan is ongoing. Titled "JSTAR" (Japanese Study of Aging 
and Retirement), it is the first “world standard” panel data on retirement in Japan and is a member of the family of the international project on aging that includes HRS (Health and Retirement Study), ELSA (English Longitudinal Survey on Aging) and SHARE (Survey on Health, Ageing and Retirement in Europe). JSTAR was begun in 2007 and has entered the second wave (Ichimura, Hashimoto, and Shimizutani (2009)). This long-term panel data provides unique opportunities to explore the pathways of retirement and their determinants of the Japanese people, who experience the longest retirement process and enjoy the longest life expectancy in the world. 


\section{References}

Clark, Robert and Naohiro Ogawa (1997). "Transitions from Career Jobs to Retirement in Japan,” Industrial Relations, vol. 36, no. 2, pp. 255-270.

Gustman, Alan, Olivia Mitchell and Thomas Steinmeier (1995). "Retirement Measures in the Health and Retirement Study,” Journal of Human Resources, vol. 30 (supplement), S. 57-83.

Ichimura, Hidehiko, Hideki Hashimoto, and Satoshi Shimizutani (2009). “JSTAR First Results: 2009 Report,” RIETI Discussion Paper Series 09-E-047. Research Institute on Economy, Trade and Industry, Project on Intergenerational Equity and Center for Intergenerational Studies (CIS), Hitotsubashi University, Discussion paper, no. 443-447.

Lazear, Edward (1986). "Retirement from the Labor Force,” in Orley C. Ashenfelter and Richard Layard eds. Handbook of Labor Economics, volume 1 (Chapter 5), pp. 305-355, North-Holland.

Lumsdaine, Robin and Olivia S. Mitchell (1999). “New Developments in the Economic Analysis of Retirement," Orley C. Ashenfelter and David Card eds. Handbook of Labor Economics, volume 3C (Chapter 49), pp. 305-355. pp. 3261-3307, North-Holland.

OECD (2008). Ageing and Employment Policies-Statistics on Average Effective Age of Retirement.

Oshio, Takashi, Akiko Sato Oishi and Satoshi Shimizutani (2009). "Social Security Reforms and Labor Force Participation of the Elderly in Japan,” Japanese Economic Review, forthcoming.

Oshio, Takashi, Satoshi Shimizutani and Akiko Sato Oishi (2008). "Does Social Security Induce Withdrawal of the Old from the Labor Force and Create Jobs for the Young? The Case of Japan” in Jonathan Gruber and David Wise eds. Social Security Programs and Retirement around the World: The Relationship to Youth Employment, forthcoming.

Rebick, Marcus (1995). "Rewards in the Afterlife: Late Career Job Placements as Incentives in the Japanese Firms,” Journal of the Japanese and International Economies, vol. 9, no. 1, pp. 1-28.

Rust, John (1989). “A Dynamic Programming Model of Retirement Behavior,” in David Wise eds. The Economics of Aging, pp.359-398, University of Chicago Press

Seike, Atsushi and Yatsuhiro Yamada (2004). Koureisha Shugyo no Keizaigaku (Economic Analysis of Labor Supply of the Elderly), Nihon Keizai Shimbun sha, Tokyo. [in Japanese].

Shimizutani, Satoshi and Takashi Oshio (2009). “New Evidence on Initial Transition from 
Career Job to Retirement in Japan,” Project on Intergenerational Equity and Center for Intergenerational Studies (CIS), Institute of Economic Research, Hitotsubashi University, Discussion paper, no. 430.

Shimizutani, Satoshi and Izumi Yokoyama (2009). "Has Japan’s Long-Term Employment Practice Survived? Developments since the 1990s," Industrial and Labor Relations Review, vol. 62, no. 3, April 2009, pp. 311-324. 
Figure 1: Labor force participation rate since 1980

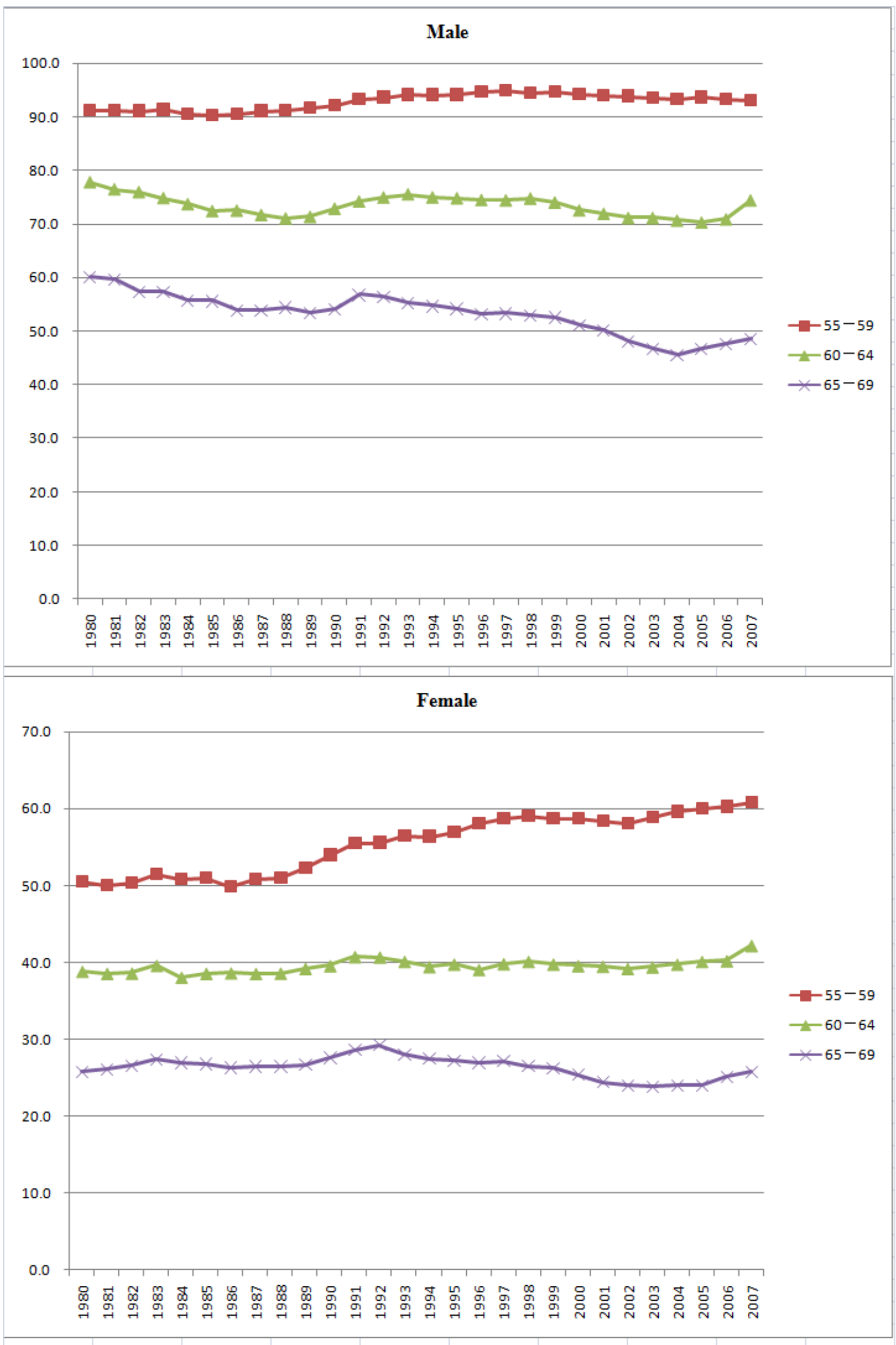




\section{Figure 2: The proportion of the retired by a variety of definitions}

(1) Definition 1: Those who have already permanently stopped working for a salary.

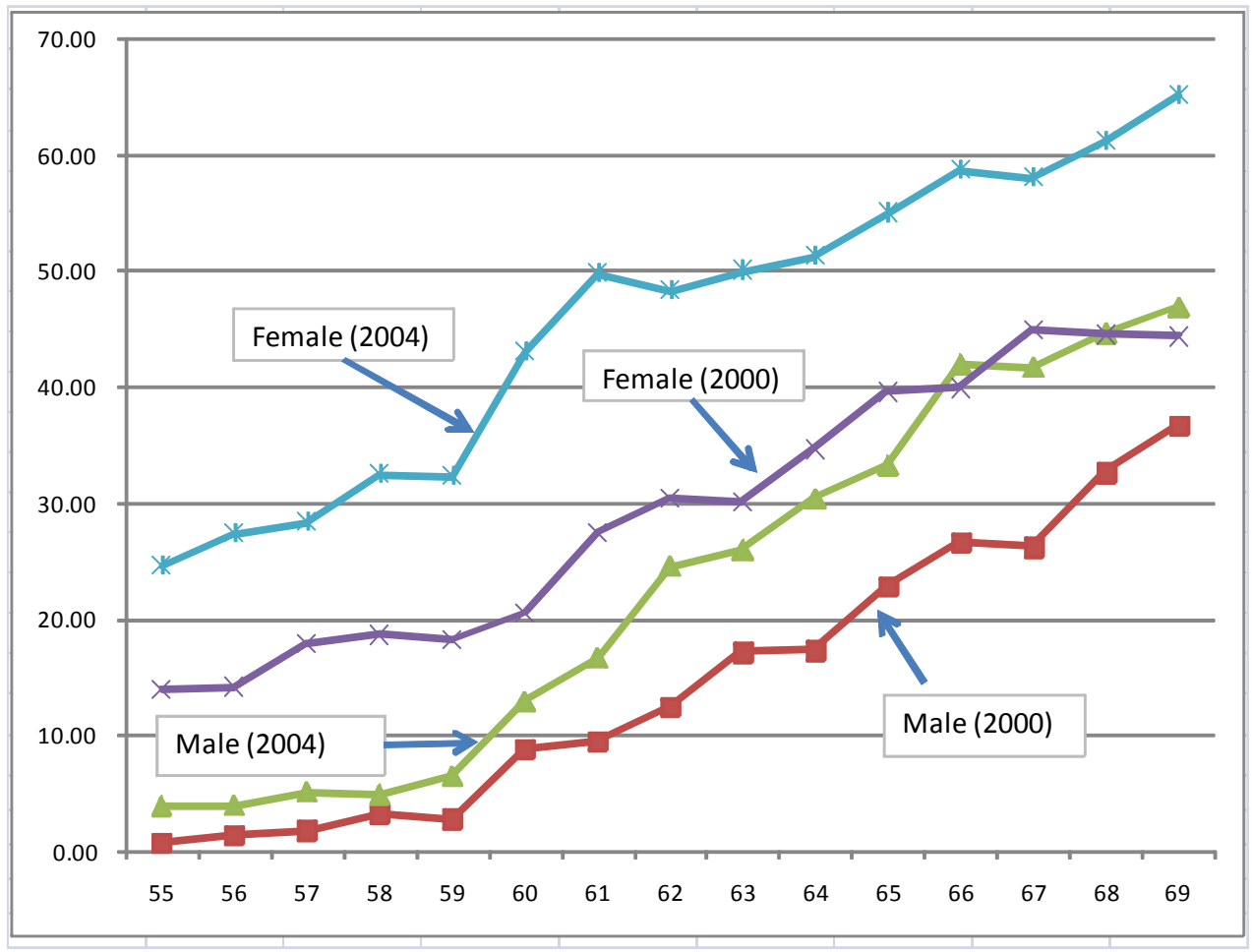

(2) Definition 2: Those who do not usually work.

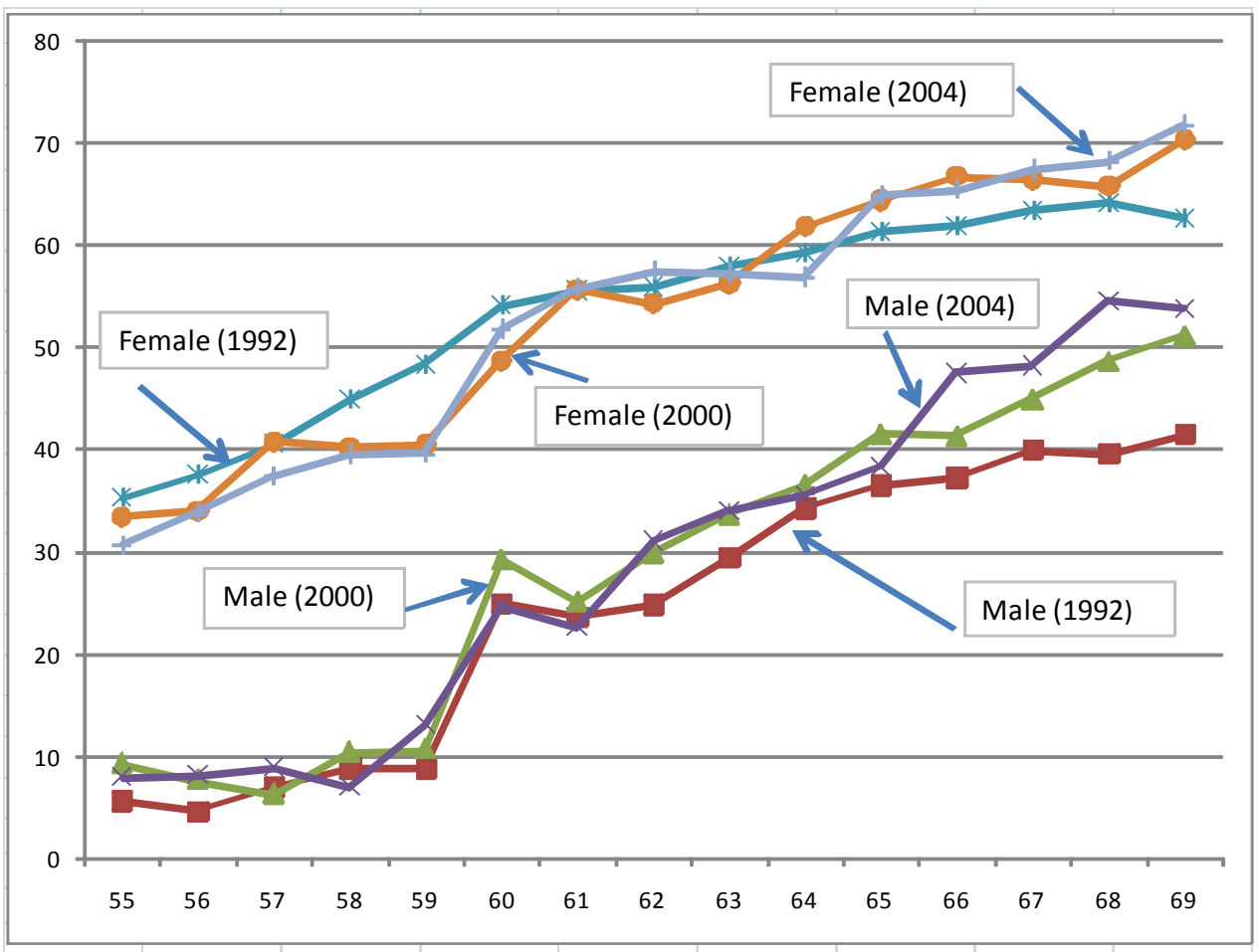


(3) Definition 3: Those who did not work and did not intend to work in the previous month.

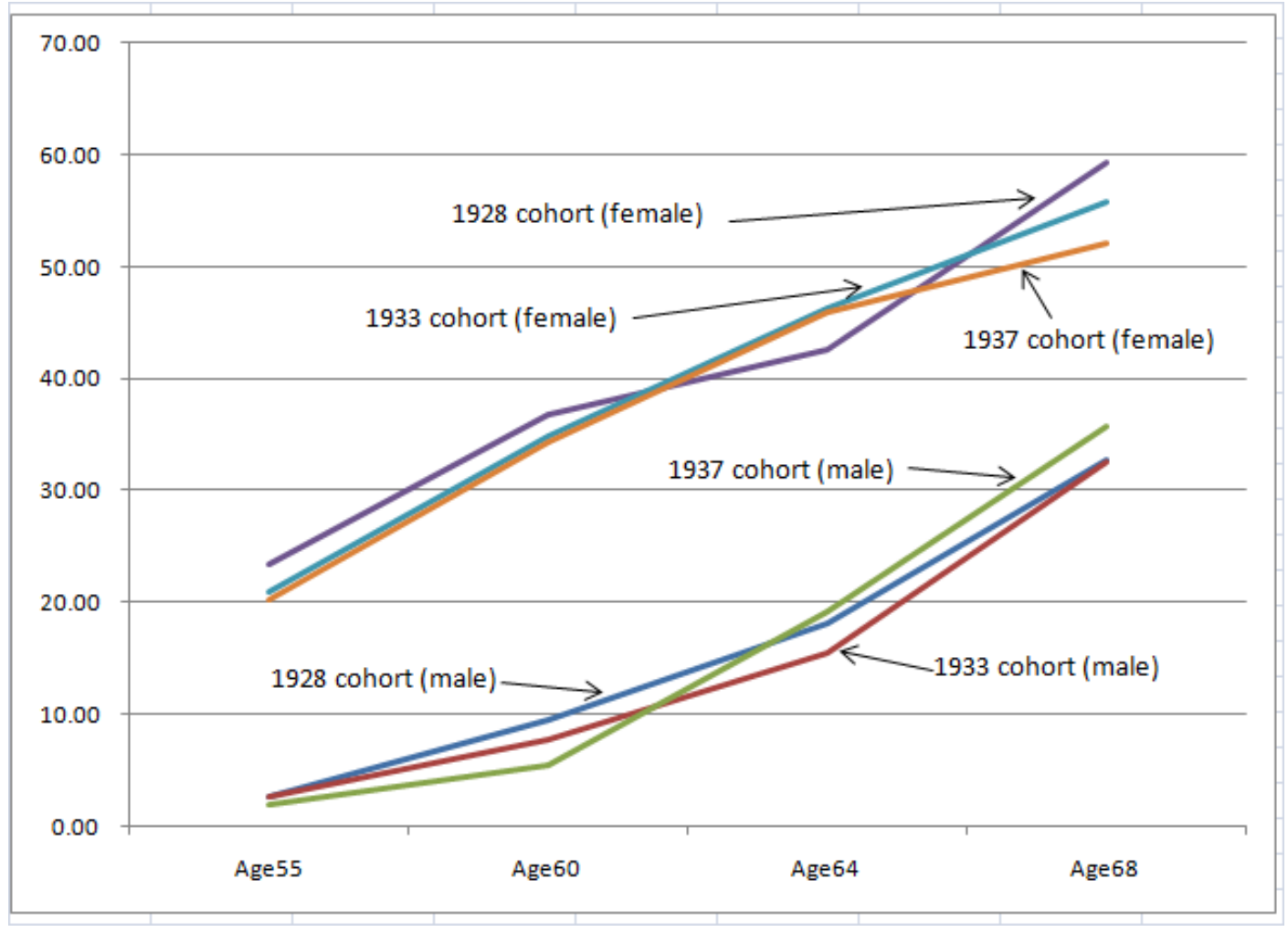

(4) Definition 4: Those who did not work and did not intend to work in the previous month or those who are unemployed searching for a short-term job or those who are employed on a non full-time basis.

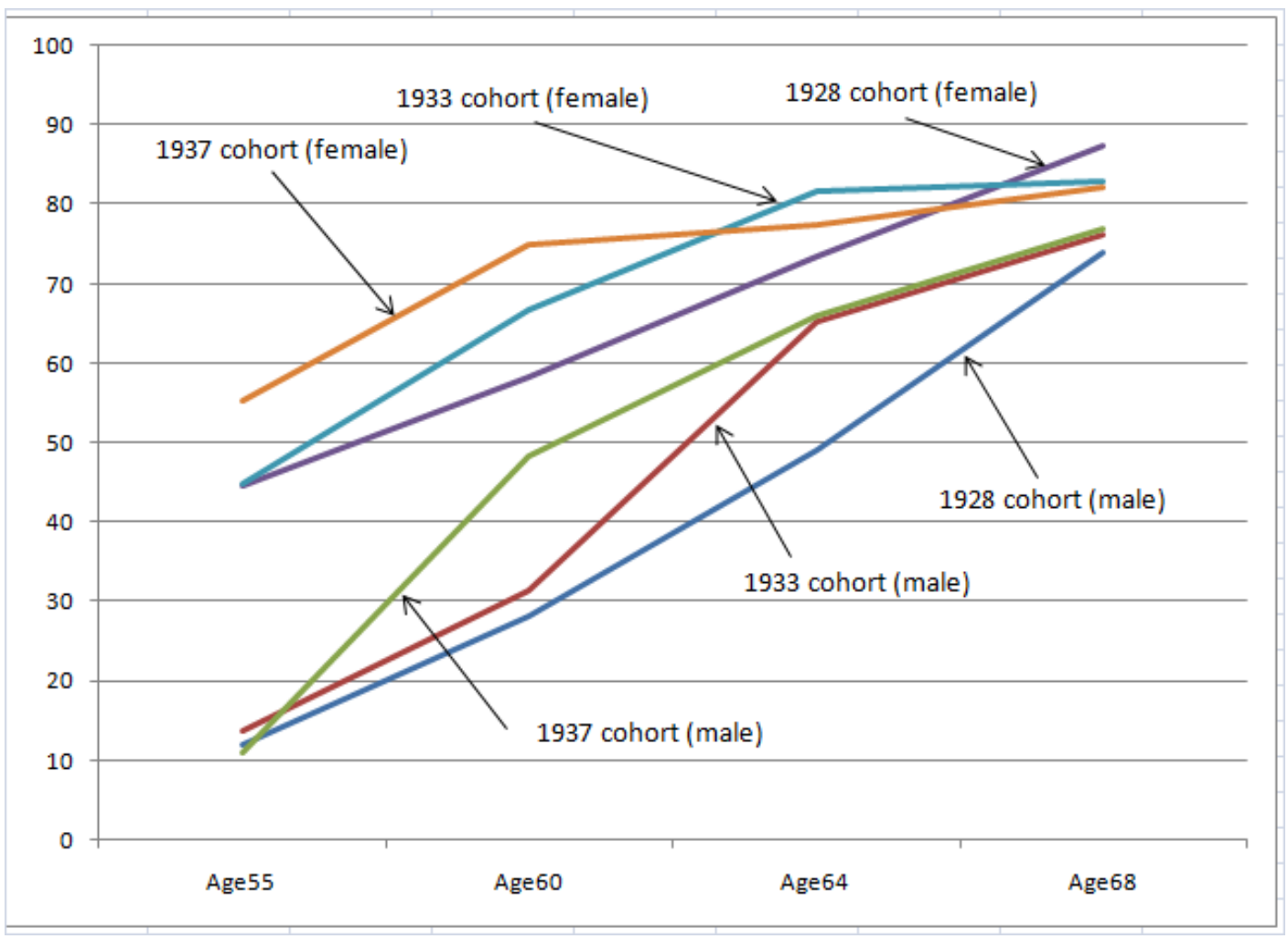


(5) Definition 5: Those who receive some public pension benefits.

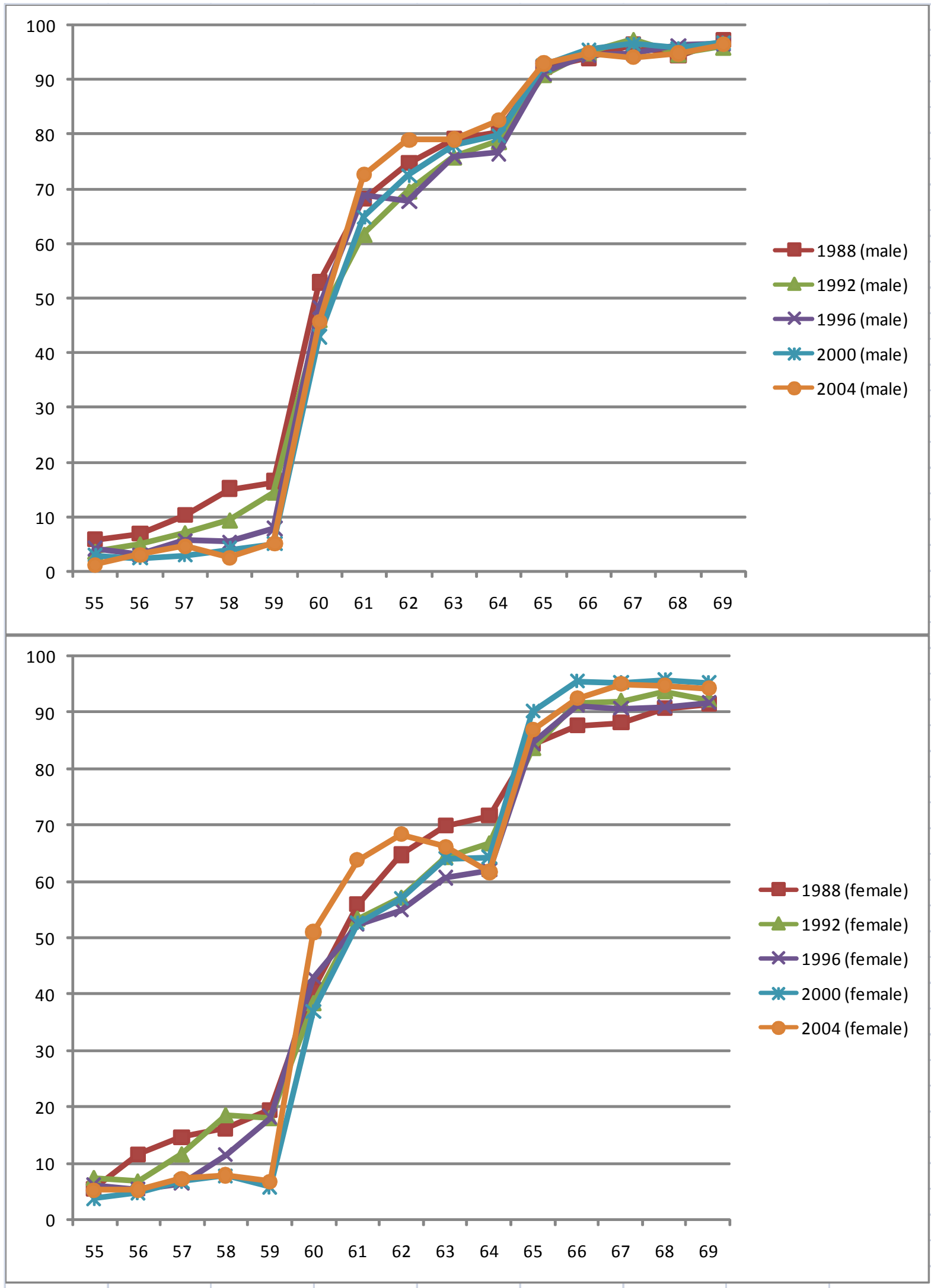


Figure 3: Distribution of actual retirement age

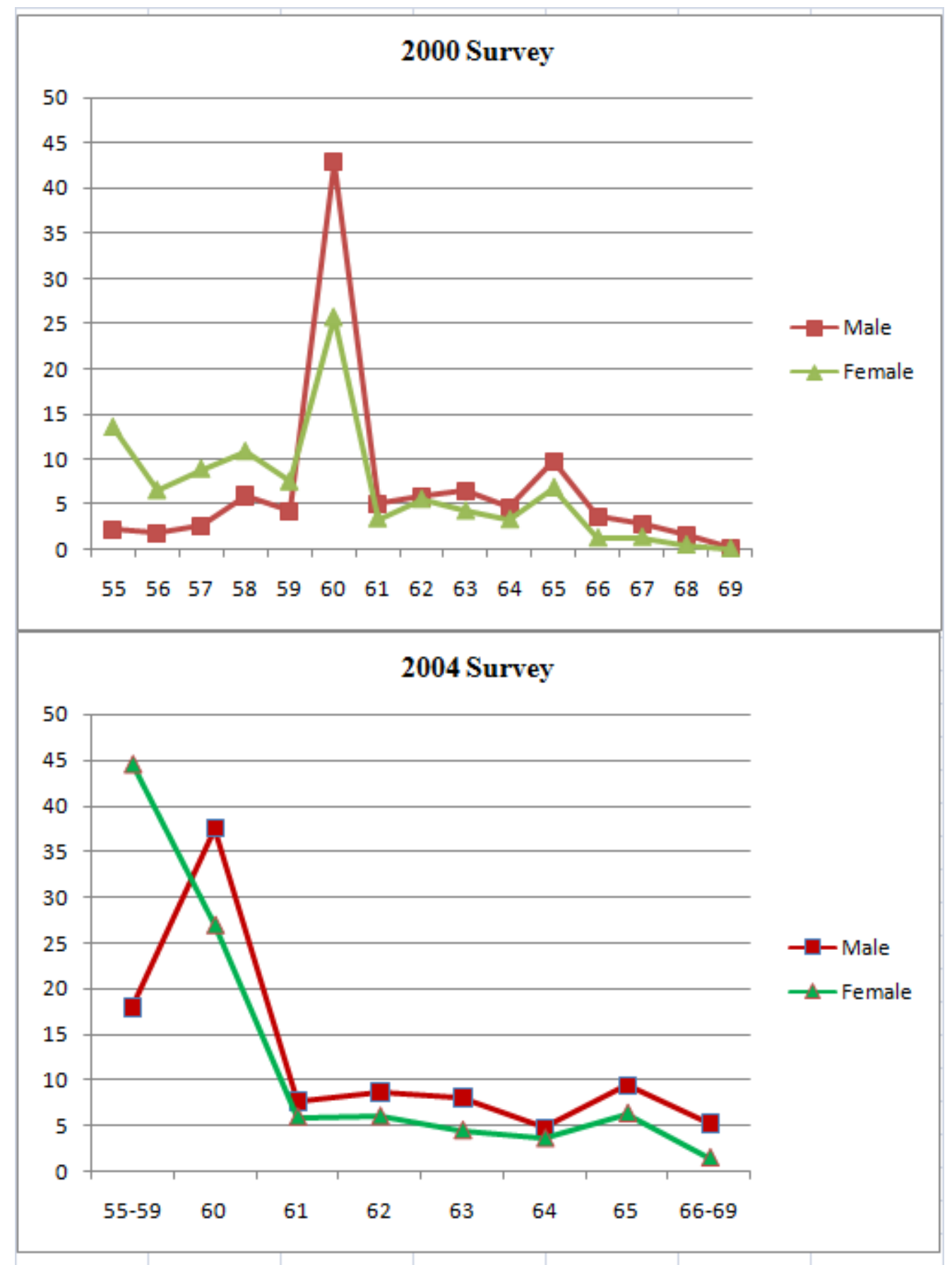




\section{Figure 4: Survival analysis of actual retirement age}

(1) Education

A. Males

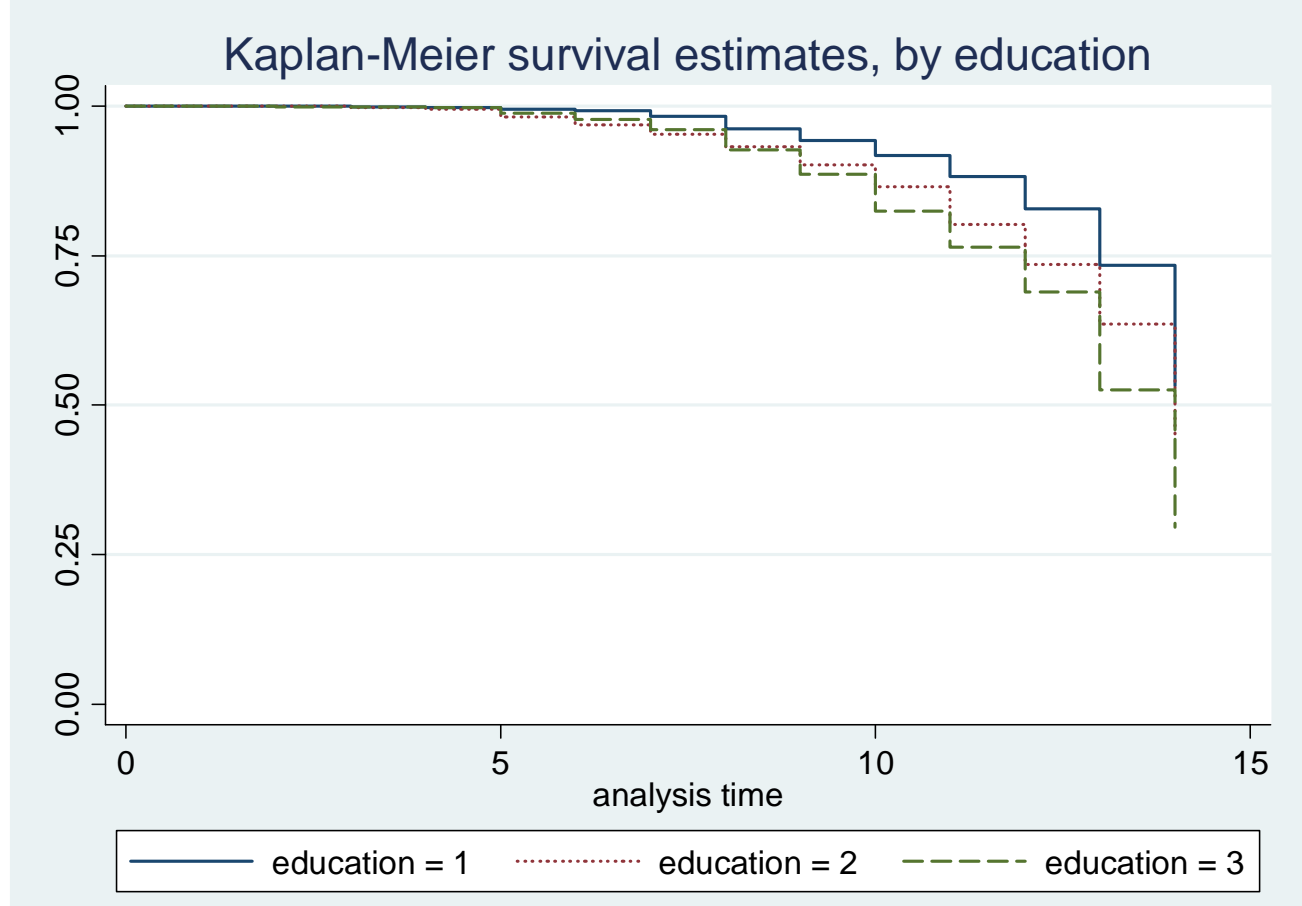

B. Females

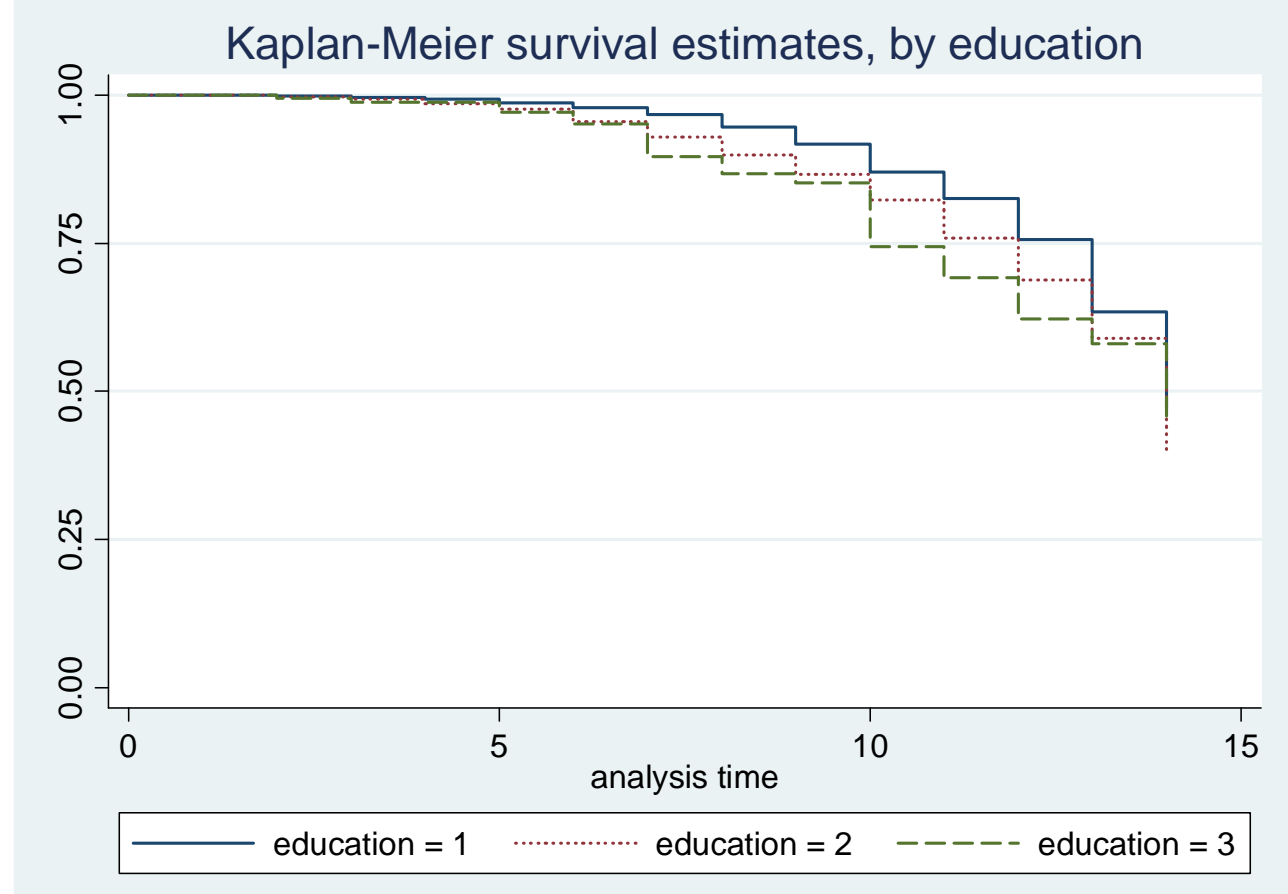

Note: Education 1 corresponds to junior high school graduates; Education 2 attended senior high school or were two year college graduates; and Education 3 were graduates of university or higher. 
(2) Job type before retirement

A. Males

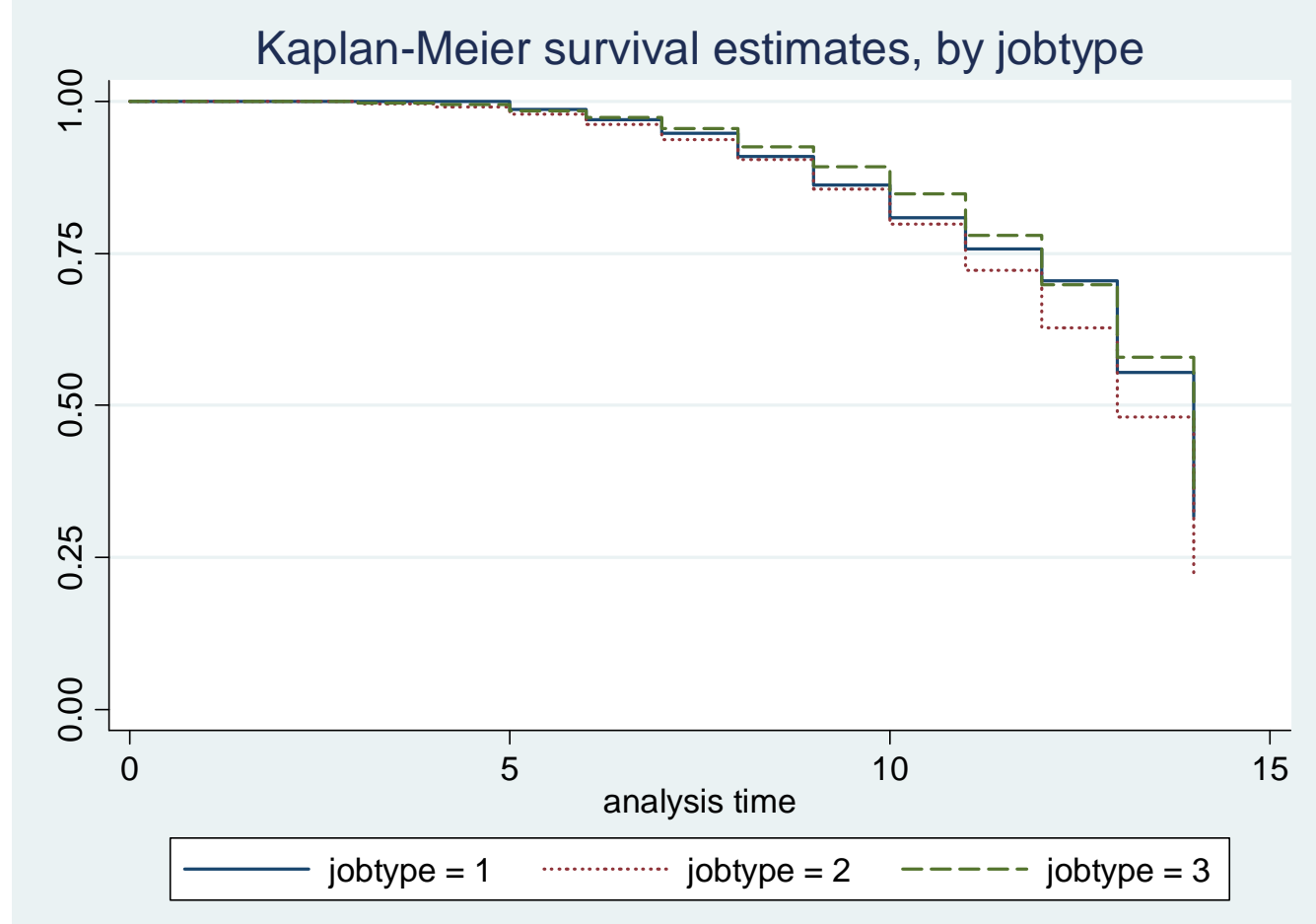

B. Females

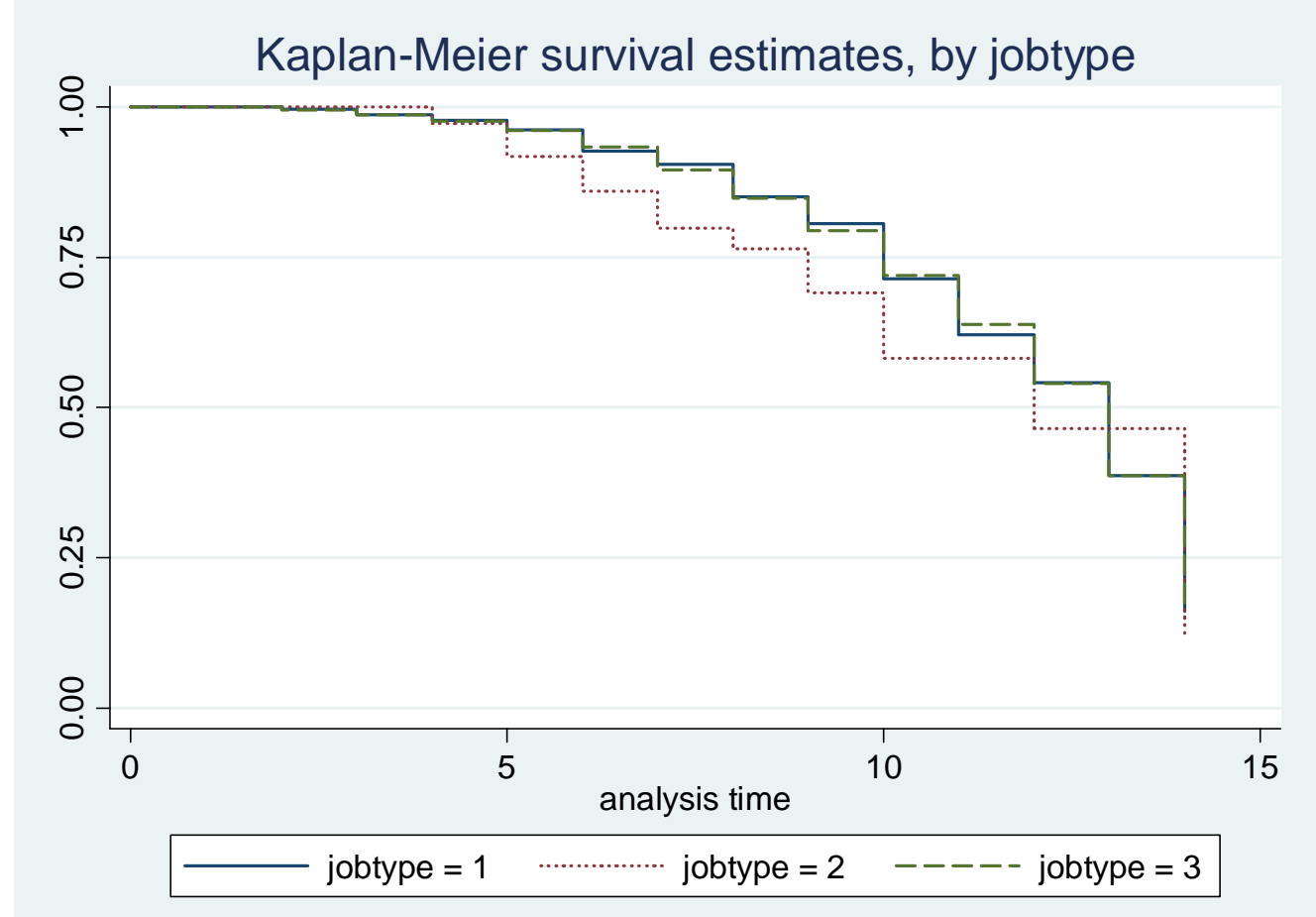

Note: Job Type 1 corresponds to experts or technicians; Job Type 2 corresponds to managers; and Job Type 3 corresponds to others which are not included in Type 1 or Type 2. 
(3) Public pension benefits

A. Males

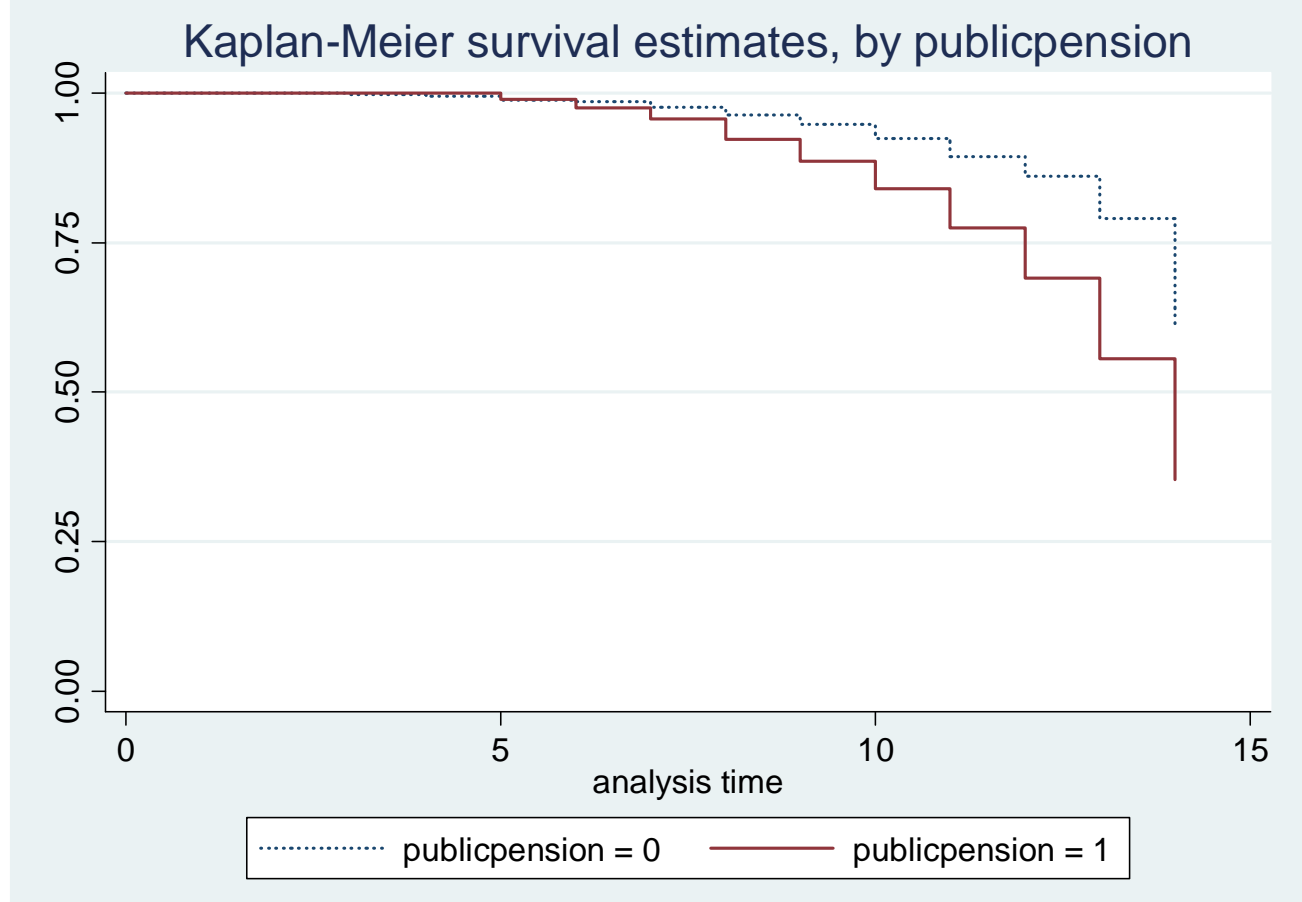

B. Females

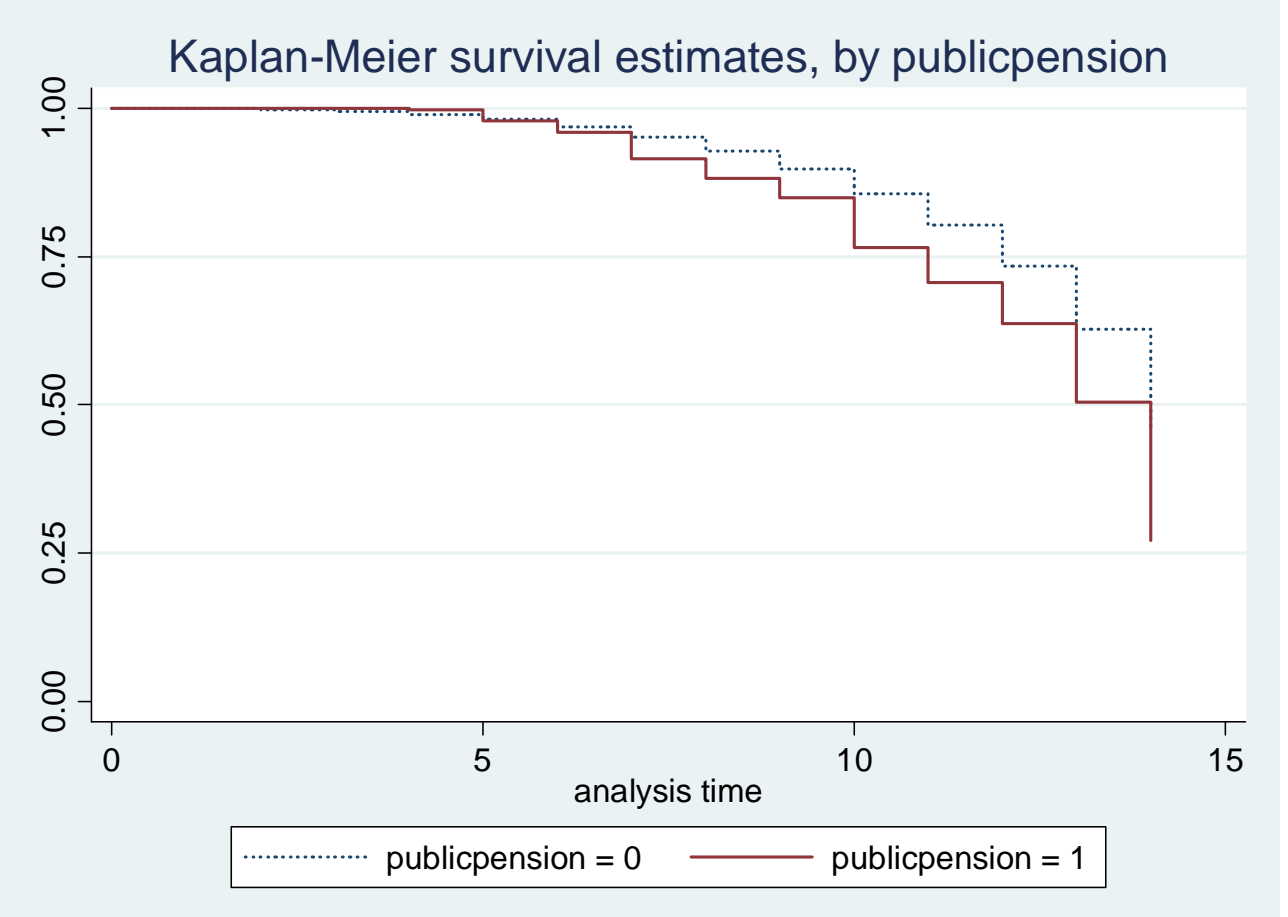

Note: 0 corresponds to those whose monthly benefit is less than 150,000 yen (median) and 1 corresponds to those whose monthly benefit is equal to or greater than 150,000 yen. 


\section{Figure 5: Survival analysis of expected retirement age}

(1) Health status

A. Males

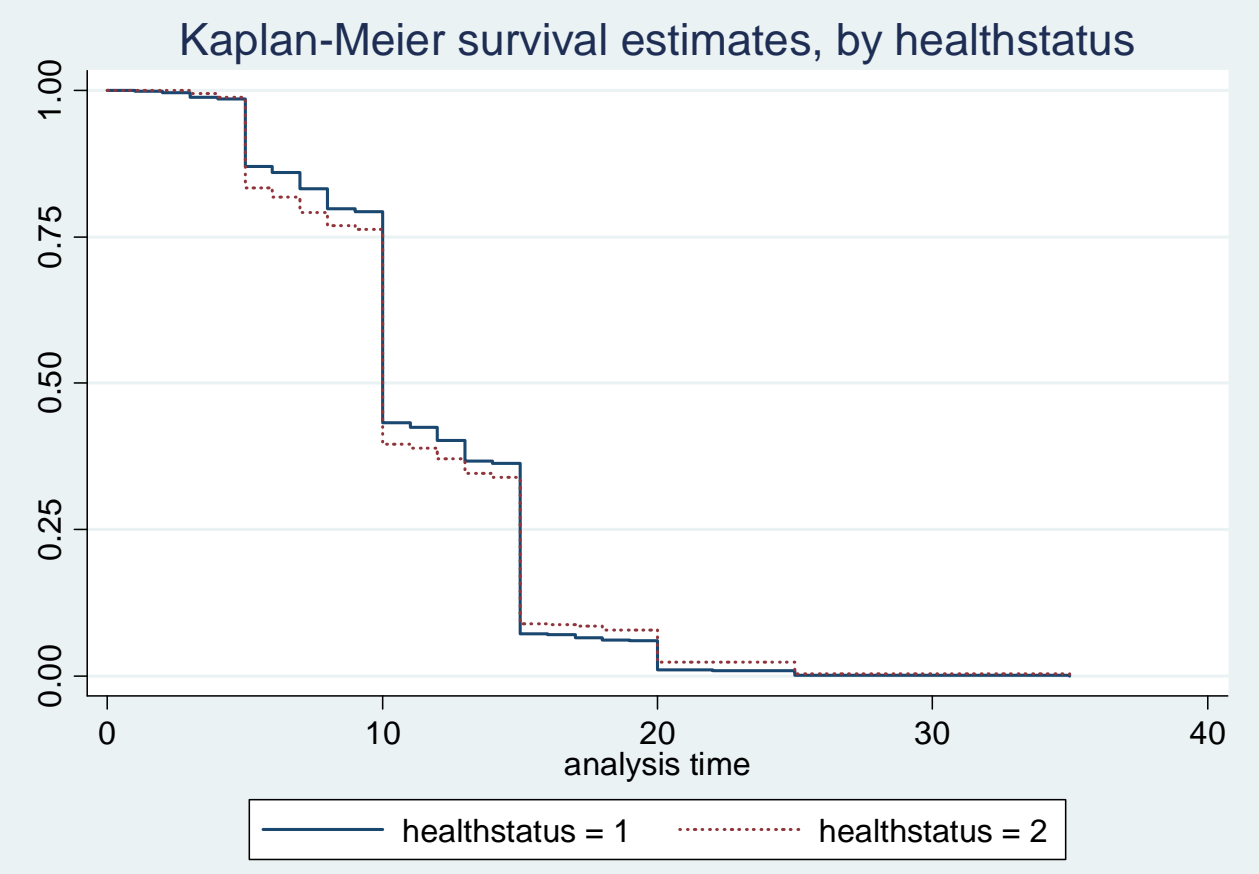

B. Females

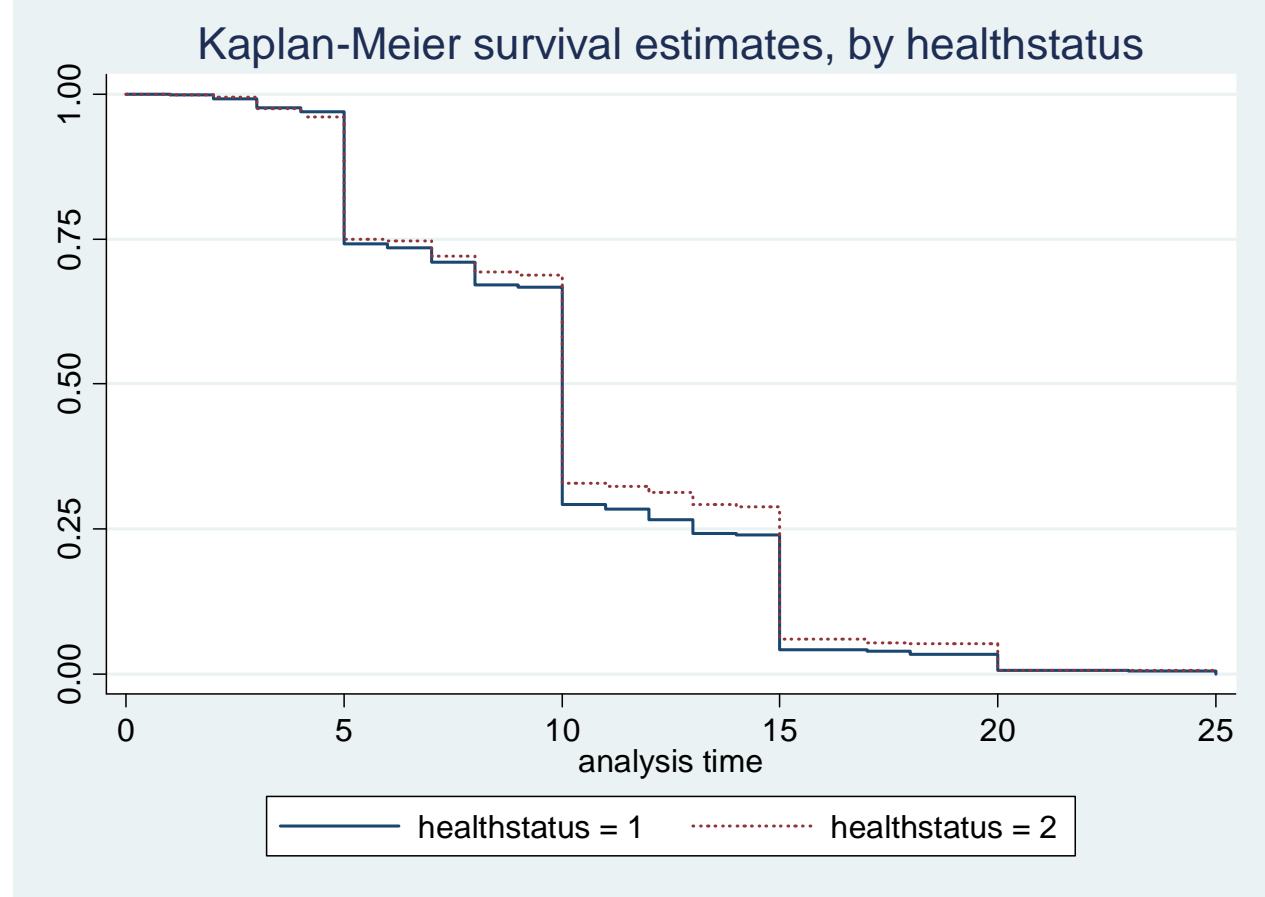

Note: Health 1 corresponds to those whose reported "healthy;" Health 2 corresponds to those who reported "not healthy" or "sick." 


\section{(2) Job satisfaction (males)}

A. Earnings

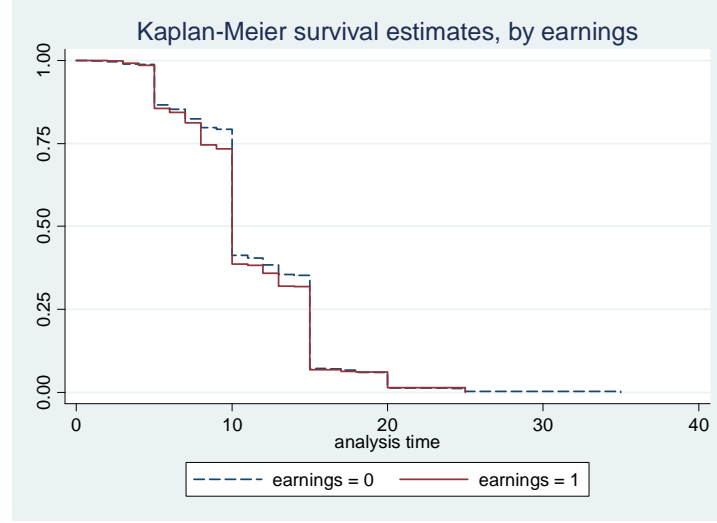

C. Workplace equipment/environment

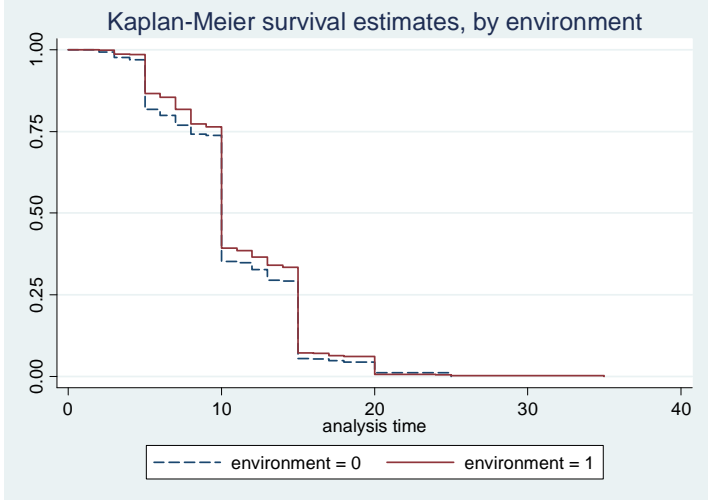

E. Utilization of skills and knowledge

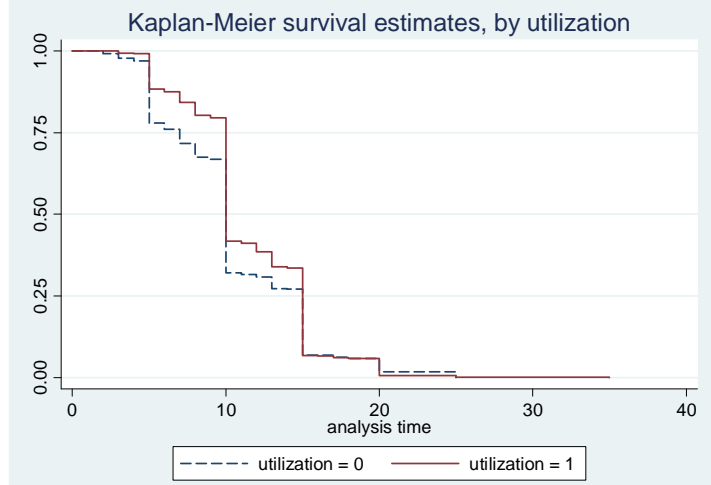

B. Working hours

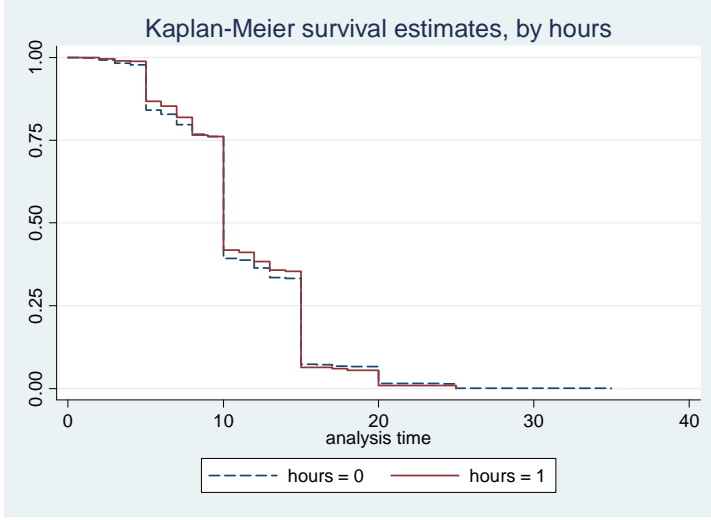

D. Human relationships at workplace

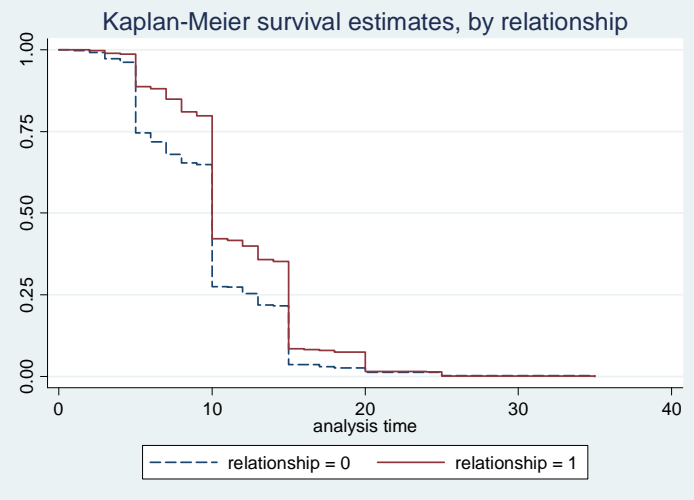

F. Job achievement

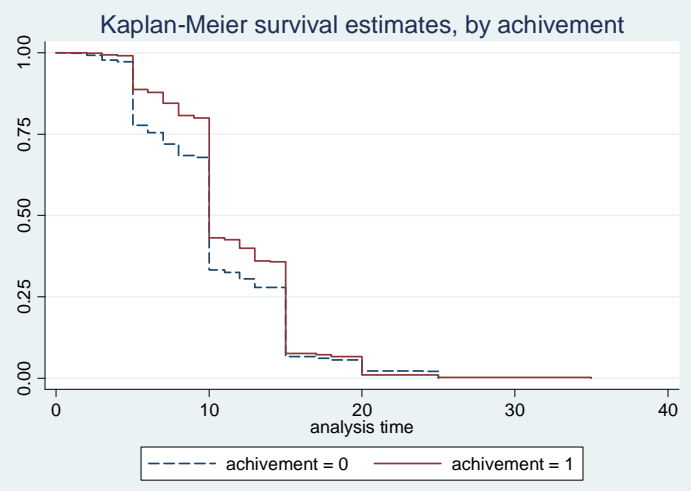

(Note) In all figures, 0 stands for the unsatisfied and 1 for the satisfied. 


\section{(3) Job satisfaction (females)}

\section{A. Earnings}

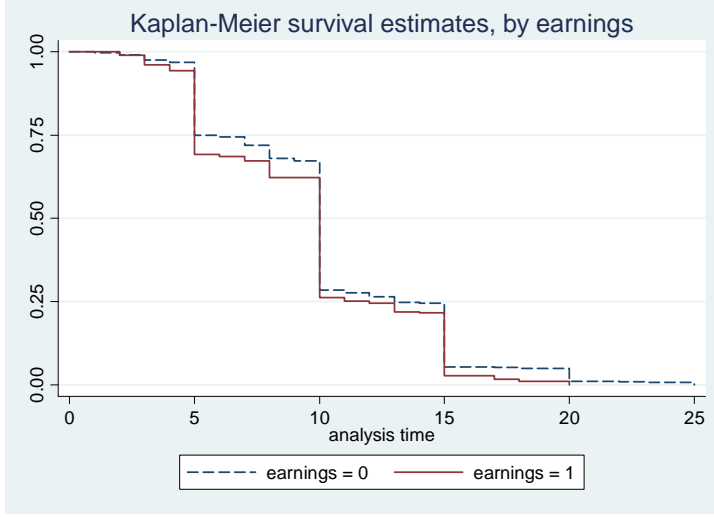

C. Workplace equipment/environment

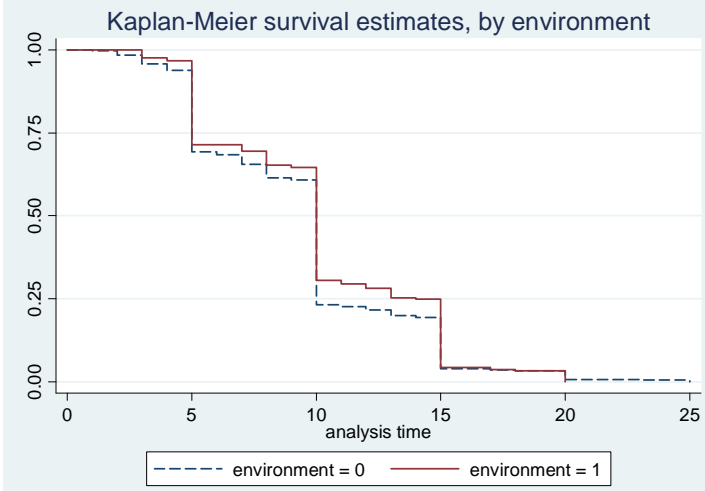

E. Utilization of skills and knowledge

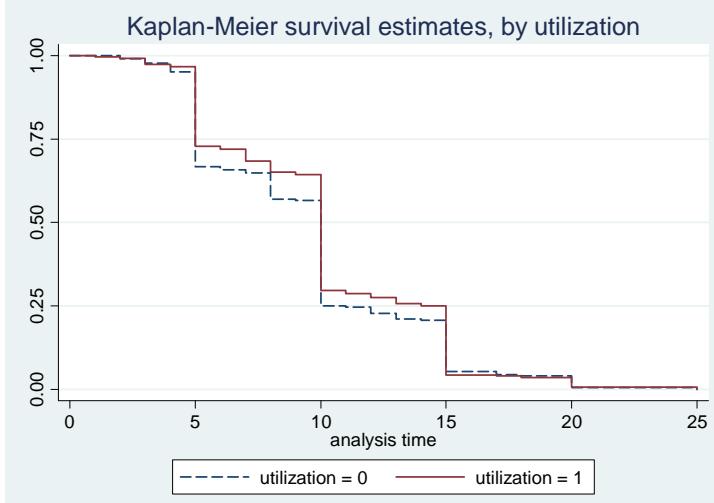

B. Working hours

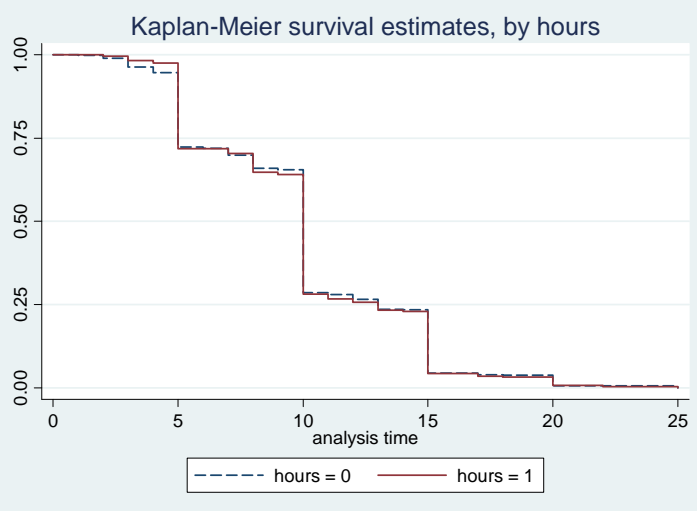

D. Human relationships at workplace

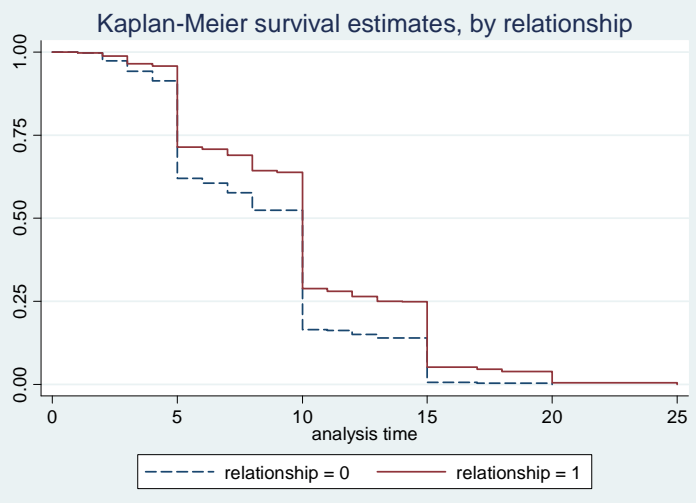

\section{F. Job achievement}

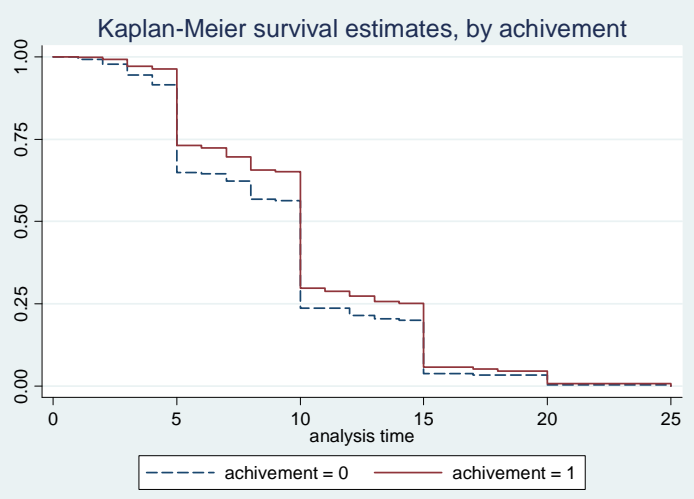

Note: In all figures, 0 stands for the dissatisfied and 1 for the satisfied. 
(4) Family size

A. Males

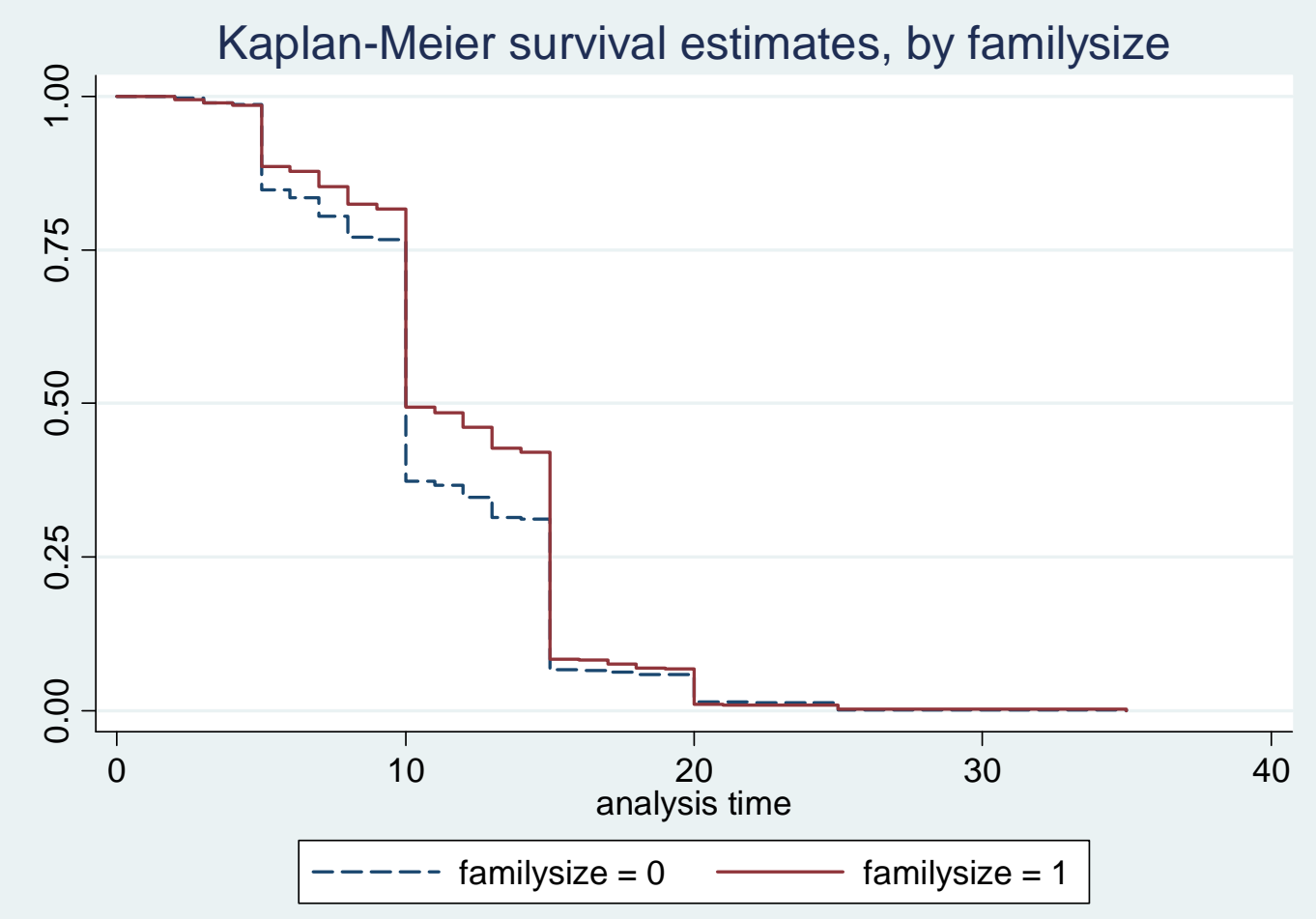

B. Females

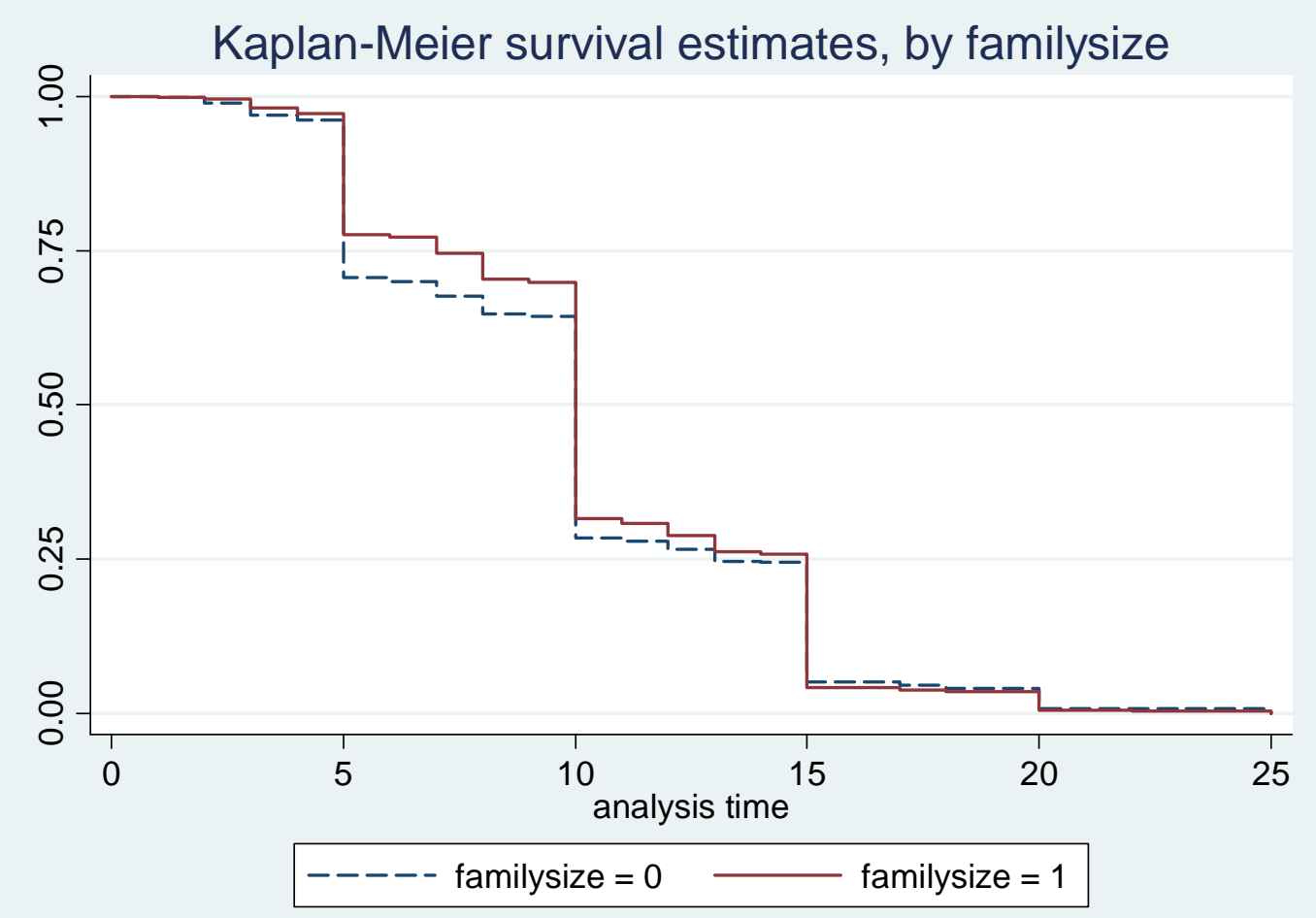

Note: 0 corresponds to those whose family size is 1 or 2 including the respondent, and 1 corresponds to those whose family size is 3 or more. 